
regional cerebral blood flow in major

SUBJECT AREAS: NEUROANATOMY

NEUROIMAGING

NEUROSCIENCE

IMAGING

Received

23 June 2011

Accepted

6 February 2012

Published

8 March 2012

Correspondence and requests for materials should be addressed to J.S. (jonathansavitz@ hotmail.com) \title{
depressive disorder
}

\author{
Jonathan Savitz' ${ }^{1,2,3}$, Allison C. Nugent 1,4, Dara M. Cannon 5 , Paul J. Carlson' ${ }^{6}$ Rebecca Davis', \\ Alexander Neumeister ${ }^{7}$, Denise Rallis-Frutos' ${ }^{1}$, Steve Fromm' ${ }^{1}$ Peter Herscovitch ${ }^{8}$ \& Wayne C. Drevets ${ }^{1,2,9}$
}

\footnotetext{
'Section on Neuroimaging in Mood and Anxiety Disorders, Mood and Anxiety Disorders Program, NIH/NIMH, Bethesda, MD, ${ }^{2}$ Laureate Institute for Brain Research, Tulsa, OK, ${ }^{3}$ Department of Medicine, Tulsa School of Community Medicine, Tulsa, OK, ${ }^{4}$ Experimental Therapeutics, Mood and Anxiety Disorders Program, NIH/NIMH, Bethesda, MD, ${ }^{5}$ Clinical Neuroimaging Laboratory, Psychiatry, National University of Ireland Galway, Ireland, ${ }^{6}$ Salt Lake City VA and Department of Psychiatry, University of Utah, Salt Lake City, UT, ${ }^{7}$ Department of Psychiatry, Mount Sinai School of Medicine, New York, NY, ${ }^{8}$ Clinical Center, National Institutes of Health, Bethesda, MD, ${ }^{9}$ The University of Oklahoma College of Medicine, Department of Psychiatry, Tulsa, OK.
}

Individuals with major depressive disorder (MDD) display abnormal neurophysiological responses to psychological stress but little is known about their neurophysiological responses to physiological stressors. Using $\left[{ }^{15} \mathrm{O}\right]-\mathrm{H}_{2} \mathrm{O}$ positron emission tomography we assessed whether the regional cerebral blood flow ( $\mathrm{rCBF}$ ) response to arterial cannulation differed between patients with MDD and healthy controls (HCs). Fifty-one MDD patients and $62 \mathrm{HCs}$ were scanned following arterial cannulation and $15 \mathrm{MDD}$ patients and 17 HCs were scanned without arterial cannulation. A region-of-interest analysis showed that a significantly increased $\mathrm{rCBF}$ of the anterior cingulate cortex and right amygdala was associated with arterial cannulation in MDD. A whole brain analysis showed increased $\mathrm{rCBF}$ of the right post-central gyrus, left temporopolar cortex, and right amygdala during arterial cannulation in MDD patients. The rCBF in the right amygdala was significantly correlated with depression severity. Conceivably, the limbic response to invasive physical stress is greater in MDD subjects than in HCs.

ndividuals with major depressive disorder (MDD) show altered behavioral ${ }^{1}$, neuroendocrine ${ }^{2}$, autonomic ${ }^{3}$, and neurophysiological ${ }^{4}$ responses to psychological stress. Neuroimaging paradigms have therefore been developed which implicitly or explicitly attempt to mimic aspects of the social environment in order to better model neural responses to psychosocial stress, and thereby improve our understanding of MDD. Stimuli have taken the form of emotionally-valenced words or visual stimuli, sad, angry or frightened faces, and recordings of critical comments.

In aggregate, the results of these studies suggest that MDD is characterized by a dysregulation of the visceromotor network, which regulates endocrine and behavioral responses to stress ${ }^{5}$. In particular, there is evidence for a reduction in "top-down" cortical (prefrontal cortex) control over structures involved in mediating the visceral and behavioral aspects of emotional behavior, such as the anterior insula (AI), ventral striatum, mediodorsal thalamus, hippocampal subiculum, amygdala, hypothalamus and brain-stem nuclei.

Nevertheless, the functional imaging data are largely based on responses to what are, by practical and ethical necessity, relatively subtle and situationally-constrained emotional or psychosocial interventions rather than responses to both non-social and physiological stressors outside of the laboratory. One such environmental stressor, which has been understudied in patients who meet DSM-IV criteria for MDD, is the response to robust physiological stressors involving pain or mildly invasive procedures.

While conducting PET neuroreceptor mapping studies of MDD, our laboratory routinely acquired ${ }^{15} \mathrm{O}-\mathrm{H}_{2} \mathrm{O}$ regional cerebral blood flow (rCBF) scans prior to neuroreceptor imaging to facilitate data processing and/or tracer modeling. For some of these studies, radial arterial cannulation is necessitated by the need for an arterial input function. This mildly invasive procedure typically induces mild-to-moderate levels of pain (despite the application of local anesthetic agents), possibly via stimulation of the radial nerve ${ }^{6}$, and activates the neural systems implicated in stress biology, including the limbic-hypothalamic-pituitary-adrenal (HPA) axis ${ }^{7}$, resulting in elevated cortisol $^{8}$, and a vascular sympathetic autonomic response. Since a tight coupling (positive correlation) exists between changes in $\mathrm{rCBF}$ and local terminal field metabolic activity ${ }^{9,10}$, the methodological requirements of 
these neuroreceptor PET studies afforded us an opportunity to study the neurophysiological response of MDD patients and healthy controls to a more invasive and aversive stressor than has been used in previous neuroimaging studies.

The aim of our current study was to test whether neurophysiological regulation of response to an unpleasant physiological stressor is modified by MDD. Specifically, we aimed to test whether compared to $\mathrm{HC}$ subjects, MDD patients show a greater difference in $\mathrm{rCBF}$ between high and low stress experimental conditions. That is, are depressed subjects more sensitive neurophysiologically to an invasive stressor than healthy controls?

Stress responses are mediated by the sympathetic-adrenomedullary (SAM) and the HPA axes, resulting in increased release of epinephrine, norepinephrine, and cortisol, respectively ${ }^{11}$. In two independent cohorts we previously found that compared to healthy controls, depressed patients show increased cortisol release in response to arterial cannulation ${ }^{8,12}$. Limbic structures such as the amygdala, which project directly to the paraventricular nucleus (PVN) of the hypothalamus, regulate stress-induced glucocorticoid secretion by disinhibiting cortisol-releasing factor (CRF) release from the $\mathrm{PVN}^{13}$. Conversely, there is an extensive body of research demonstrating that epinephrine, norepinephrine, and cortisol influence amygdala function ${ }^{14,15}$. Based on these data, as well as the extensive literature on the role of the amygdala in depression and pain, we expected to find increased $\mathrm{rCBF}$ of the amygdala in MDDart+ patients.
This study also specifically investigates two regions of interest (ROIs) comprising the cortical components of the stress matrix that process the emotional, endocrine and autonomic dimensions of aversive stimulation - the anterior cingulate (ACC) and anterior insular cortices ${ }^{16,17}$. In their meta-analysis, Apkarian et al. show that 45 out of 68 studies of pain induction in healthy subjects reported activity changes in insula, the primary viscerosensory and nociceptive cortex ${ }^{18}$. This meta-analysis also noted changes in ACC activity in 46 of 68 studies, consistent with evidence that the ACC modulates amygdala-driven CRF release ${ }^{19}$ in response to noxious emotional or physiological stimuli ${ }^{18}$.

\section{Results}

Demographic and Clinical Variables. These data are shown in Table 1.

There was no significant difference between the 4 groups in gender distribution $\left(\mathrm{x}^{2}=1.0, \mathrm{p}=0.81\right)$ or age at scan $(\mathrm{F}=1.9, \mathrm{p}=0.13)$. No significant difference was found between the MDD patients who underwent arterial cannulation (MDDart+) and MDD patients who did not undergo arterial cannulation (MDDart-) groups on the number of weeks medication free $(t=1.2, \mathrm{p}=0.24)$, age at onset $(\mathrm{t}=0.7, \mathrm{p}=0.50)$, or illness duration $(\mathrm{t}=1.2, \mathrm{p}=0.25)$.

Both the art + and the art- MDD groups scored higher than the art + and art- HC groups on the MADRS $(\mathrm{F}=215, \mathrm{p}<0.001)$ but there was no significant difference between the art + and art- MDD

\begin{tabular}{|c|c|c|c|c|c|c|c|c|}
\hline \multirow{2}{*}{ Trait } & \multicolumn{4}{|c|}{ Diagnosis } & \multicolumn{4}{|c|}{ Statistics } \\
\hline & MDD_art & MDD_no_art & HC_art & HC_no_art & Statistic & DF & $p$-value & Result \\
\hline $\begin{array}{l}\mathbf{N} \\
\text { Gender }\end{array}$ & 51 & 15 & 62 & 17 & $x^{2}=1.0$ & 3 & 0.81 & NS \\
\hline Males & 19 & 6 & 28 & 6 & & & & \\
\hline Females & 32 & 9 & 34 & 11 & & & & \\
\hline Percent Female & 63 & 60 & 55 & 65 & & & & \\
\hline $\begin{array}{l}\text { Age at Scan } \\
\text { NS }\end{array}$ & $37.6 \pm 9.7$ & $31.9 \pm 10.7$ & & $34.8 \pm 9.6$ & $31.9 \pm 8.4$ & $\mathrm{~F}=1.9$ & 3 & 0.13 \\
\hline $\begin{array}{l}\text { Past Medication Use (>3 weeks } \\
\text { previous; N) }\end{array}$ & & & NA & NA & & & & \\
\hline Naive & 20 & 10 & & & & & & \\
\hline$A D$ & 27 & 5 & & & & & & \\
\hline Mood Stabilizers & 7 & 2 & & & & & & \\
\hline Benzodiazepines & 2 & 1 & & & & & & \\
\hline $\begin{array}{l}\text { Weeks Medication Free } \\
\text { Age at Onset }\end{array}$ & $\begin{array}{l}93.4 \pm 120.7 \\
18.0 \pm 6.2\end{array}$ & $\begin{array}{l}27.7 \pm 9.3 \\
19.8 \pm 11.7\end{array}$ & $\begin{array}{l}\text { NA } \\
\text { NA }\end{array}$ & $\begin{array}{l}\text { NA } \\
\text { NA }\end{array}$ & $\begin{array}{l}t=1.2 \\
t=0.7\end{array}$ & $\begin{array}{l}32 \\
48\end{array}$ & $\begin{array}{l}0.24 \\
0.50\end{array}$ & $\begin{array}{l}\text { NS } \\
\text { NS }\end{array}$ \\
\hline $\begin{array}{l}\text { Years ill } \\
\text { Fom ilv History of Affective Illness (N) }\end{array}$ & $17.8 \pm 11.4$ & $13.7 \pm 9.7$ & NA & NA & $t=1.2$ & 48 & 0.25 & NS \\
\hline $\begin{array}{l}\text { Family History of Affective lilness (N) } \\
\text { Present }\end{array}$ & 31 & 11 & 0 & 0 & & & & \\
\hline Absent & 4 & 1 & 62 & 17 & & & & \\
\hline Uncertain & 16 & 3 & 0 & 0 & & & & \\
\hline $\begin{array}{l}\text { Past History of Substance/Alcohol } \\
\text { Abuse (N) }\end{array}$ & & & NA & NA & & & & \\
\hline Present & 8 & 2 & & & & & & \\
\hline Absent & 43 & 13 & & & & & & \\
\hline $\begin{array}{l}\text { Common Comorbid Disorders in } \\
\text { Sample (N) }\end{array}$ & & & NA & NA & & & & \\
\hline Panic Disorder & 5 & 3 & & & & & & \\
\hline PTSD & 4 & 4 & & & & & & \\
\hline GAD/Social Anxiety Disorder & 3 & 2 & & & & & & \\
\hline $\begin{array}{l}\text { Eating Disorder } \\
\text { Mood Ratings }\end{array}$ & 2 & 1 & & & & & & \\
\hline MADRS & $24.7 \pm 8.1$ & $22.5 \pm 5.4$ & $0.3 \pm 0.7$ & $0.5 \pm 1.2$ & $\begin{array}{l}\mathrm{t}=1.0^{\mathrm{a}} \text { and } \\
\mathrm{t}=0.7^{\mathrm{b}}\end{array}$ & $\begin{array}{c}53^{\mathrm{a}} \text { and } \\
68^{\mathrm{b}}\end{array}$ & $\begin{array}{c}0.34^{\mathrm{a}} \\
\text { and } 0.49^{\mathrm{b}}\end{array}$ & NS \\
\hline
\end{tabular}


groups $(\mathrm{t}=1.0, \mathrm{p}=0.34)$ or between the art + and art- HC groups $(\mathrm{t}=0.7, \mathrm{p}=0.49)$ on the MADRS.

Although no demographic or clinical variables differed significantly across the 4 subject groups, the MDD art + subjects were on average 5.5 years older than the MDD art- subjects. Similarly, the $\mathrm{HC}$ art + group was on average 3 years older than the $\mathrm{HC}$ artgroup. To ensure that our results were not systematically biased by age effects, we therefore added age as a covariate in the general linear model.

Imaging. ROI Analysis. Contrast A: MDDart+ versus MDDart-. MDDart+ patients displayed higher rCBF compared with MDDart- patients in the following regions (table 2 and fig. 1A): the supragenual and pregenual ACC, left posterior insula, and left and right amygdalae.
MDDart+ patients displayed lower rCBF compared with MDDart- patients in the following regions (table 2 and fig. 1B): left and right anterior insulae and the sgACC.

Contrast B: HCart+ versus HCart-. Within the predefined ROI no areas were identified where $\mathrm{rCBF}$ differed significantly between the HCart+ and HCart- groups.

Contrast $C=A-B$. The MDD patients showed a significant increase in $\mathrm{rCBF}$ in response to arterial cannulation in the right amygdala and the supragenual ACC relative to healthy controls (table 3, fig. 1C). No significant decrease in the $\mathrm{rCBF}$ of MDD patients in response to arterial cannulation stress was observed relative to healthy controls.

In post hoc assessments the flow obtained over the locus where the peak voxel-t-value was evident within the right amygdala (table 3 ) was significantly correlated (positively) with the MADRS score in the

\begin{tabular}{|c|c|c|c|c|c|c|c|c|}
\hline \multicolumn{9}{|c|}{ CONTRAST A - ROI Analysis } \\
\hline \multicolumn{9}{|c|}{ Increased rCBF in MDDart+ vs. MDDart- } \\
\hline T score & Z score & p-value & $\begin{array}{c}\text { FDR } \\
p \text {-value }\end{array}$ & \multicolumn{3}{|c|}{ Coordinates $^{a}$} & Region of Interest ${ }^{\mathrm{b}}$ & Additional Comments \\
\hline 4.25 & 4.12 & $<0.001$ & 0.006 & 2 & 32 & 15 & $A C C$, pregenual & \multirow{5}{*}{$\begin{array}{l}\text { Cluster size corrected p-value } \\
<0.001 ; \text { FWE corrected } \\
\text { p-value }=0.018 \\
\text { Cluster size corrected p-value } \\
=0.002 ; \text { FWE corrected } \\
\text { p-value }=0.031\end{array}$} \\
\hline 4.00 & 3.88 & $<0.001$ & 0.006 & 2 & 15 & 25 & ACC, supragenual & \\
\hline 3.39 & 3.32 & $<0.001$ & 0.008 & 40 & -17 & -14 & Insula, $R$ posterior insula & \\
\hline 3.33 & 3.26 & 0.001 & 0.009 & 42 & -1 & -12 & $\begin{array}{l}\text { "Insula", R temporopolar } \\
\text { cortex }\end{array}$ & \\
\hline 3.10 & 3.04 & 0.001 & 0.013 & 46 & 9 & -11 & $\begin{array}{l}\text { "Insula" R temporopolar } \\
\text { cortex }\end{array}$ & \\
\hline
\end{tabular}

CONTRAST A - ROI Analysis

Decreased rCBF in MDDart+ vs. MDDart-

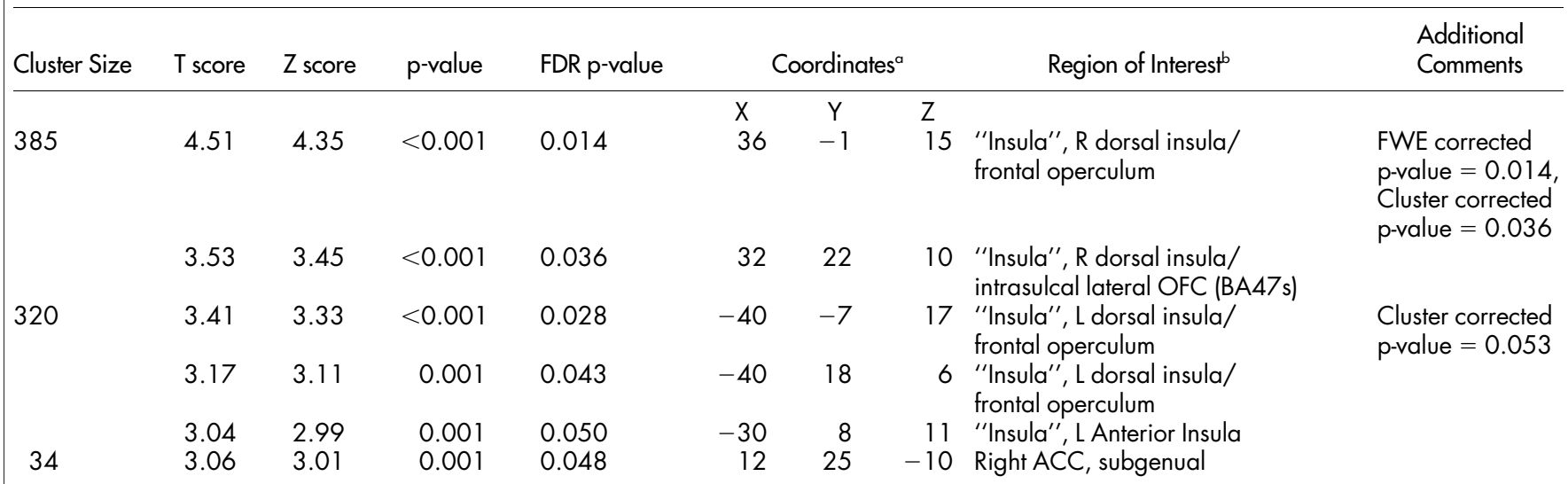

a. Coordinates correspond to the stereotaxic array of Talairach and Tournoux ${ }^{55}$ and are in $\mathrm{mm}$ from the stereotaxic origin (anterior commissure) with positive $\mathrm{x}=\mathrm{right}$, positive $\mathrm{y}=$ anterior, and positive $\mathrm{z}=$ dorsal to a plane containing both the anterior and posterior commissures.

b. The region-of-interest in which differences in normalized flow is listed first; however, because the regional template for the insula extended outside the cortex of primary interest to encompass the entire operculum, where the coordinates localized cortical areas other than the insula based on the stereotaxic coordinates (Mai et al. ${ }^{54}$; Talairach and Tournoux ${ }^{55}$; Ongur et al. ${ }^{20}$ ) these cortices are named accordingly and the ROI name appears in quotation marks (i.e., "insula").

Significance threshold for peak voxel in cluster: $\mathrm{p} \leq 0.001$.

Significance threshold for contiguous voxels: $p \leq 0.01$ and region $\geq 100 \mathrm{~mm}^{3}$ in size.

Abbreviations: $A C C=$ anterior cingulate cortex; $L=l$ eft; $O F C=$ orbitofrontal cortex; $R=$ right; $F D R=$ false discovery rate corrected $p$-value; $F W E=$ family-wise error corrected $p$-value. 
1

A
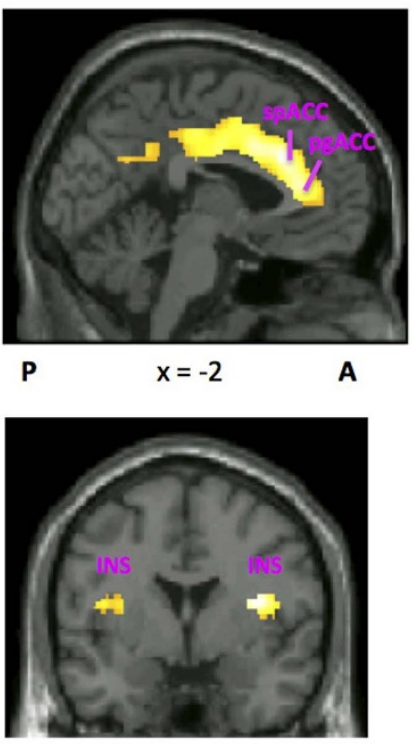

$y=-1$

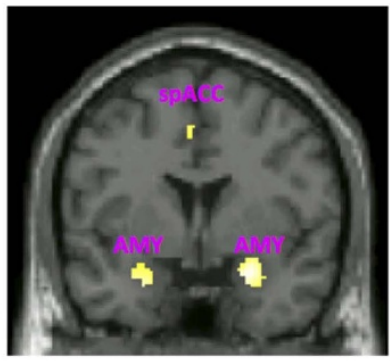

$y=2$
2

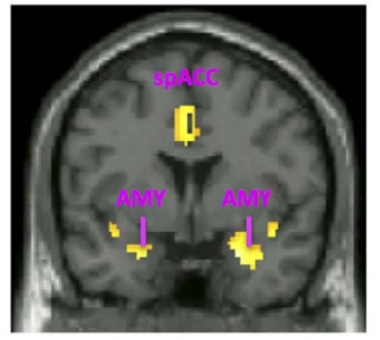

L

$y=1$

R

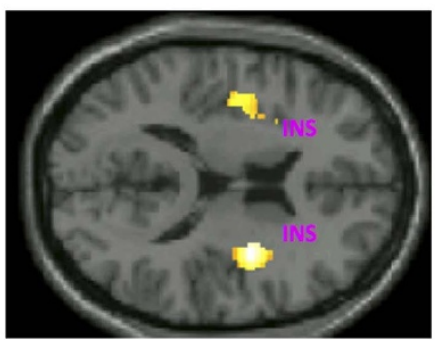

$z=15$

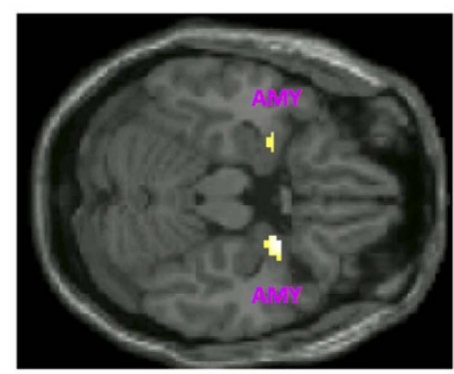

$z=-20$
3

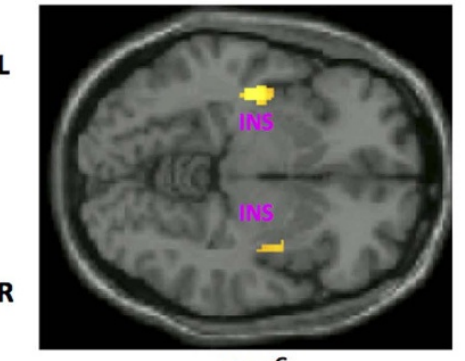

$z=-6$

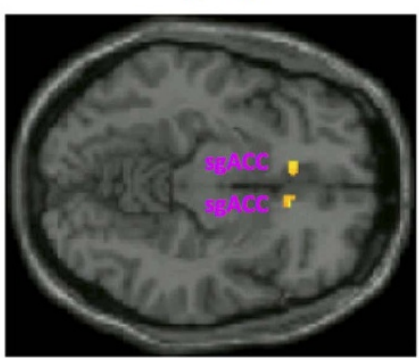

$z=-10$

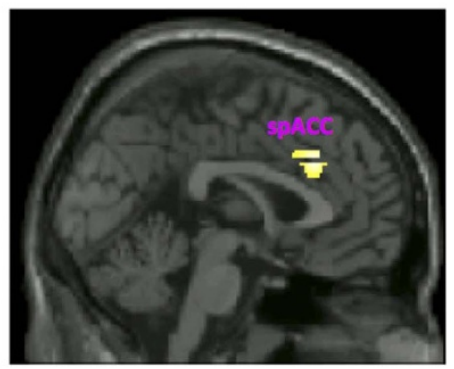

4
3
2
1
0
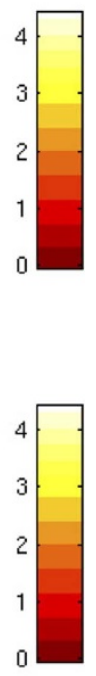

$x=0$

Figure $1 \mid$ Image sections from a statistical parametric map of voxel t-values which show regions where rCBF is significantly increased or decreased in contrasts A and C of the ROI analysis. Stereotaxic coordinates provided beneath each section image denote the distance in mm from the stereotaxic origin (anterior commissure), with positive $\mathrm{x}$ indicating right of midline (for sagittal sections), positive y indicating anterior (for coronal sections), and positive $\mathrm{z}$ indicating dorsal (for horizontal sections). Abbreviations: $\mathrm{A}=$ anterior to anterior commissure, $\mathrm{P}=$ posterior to anterior commissure, $\mathrm{L}=$ left hemisphere, $\mathrm{R}=$ right hemisphere, spACC = supragenual ACC, pgACC=pregenual ACC, AMY= amygdala, INS=insula, sgACC= subgenual ACC. Row A shows regions of the brain that show greater $\mathrm{rCBF}$ in MDDart+ versus MDDart- patients (contrast A). A1: sagittal slice showing areas where voxel tvalues show significantly increased activity in the supragenual and pregenual ACC $(x=-2, y=26, z=24)$. The posterior ACC is also evident but is below the significance threshold; A2: coronal slice showing higher activity in the amygdala, bilaterally, and in the supragenual ACC $(x=24, y=1, z=-20)$; 3 : axial slice showing elevated activity of the posterior insula, bilaterally $(x=-40, y=-12, z=-6)$. Row $B$ shows regions of the brain that demonstrate reduced flow in the MDDart+ group relative to the MDDart- group (contrast A). B1 and B2 display: coronal and axial slices, respectively, showing areas of decreased $\mathrm{rCBF}$ in the dorsal anterior insula/frontal operculum, bilaterally $(\mathrm{x}=36, \mathrm{y}=-1, \mathrm{z}=15)$, while $\mathrm{B} 3$ displays an axial slice showing decreased $\mathrm{rCBF}$ in the $\operatorname{sgACC}(\mathrm{x}=12, \mathrm{y}=25, \mathrm{z}=-10)$ MDDart + group relative to the MDDart- group. Row $\mathrm{C}$ shows regions of the brain associated with greater $\mathrm{rCBF}$ in response to arterial cannulation in the MDD+ group compared with the MDDart- group relative to differences between the HCart + and HCartgroups (contrast C). C1: coronal slice showing areas where flow is increased in the amygdala, bilaterally $(x=24, y=2, z=-20)$, C2: axial slice showing areas of increased flow of the amygdala, bilaterally $(x=24, y=2, z=-20)$, C3: sagittal slice showing region of peak rCBF in the supragenual ACC $(x=0$, $y=27, z=28)$. A4, B4, and C4: Key showing correspondence between image color and voxel t-value.

MDDart + group $(r=0.272, p=0.045)$. In the left amygdala the normalized activity showed a nonsignificant trend towards correlating positively with the MADRS score $(r=0.231, \mathrm{p}=0.076)$ (fig. 3$)$. There was no significant association between the MADRS scores and normalized activity of the right amygdala $(r=0.036, p=0.449)$ and left amygdala $(r=-0.33, p=0.454)$ in the MDDart- group. There was also no significant correlation between the normalized activity of the peak voxel in the supragenual ACC cluster and MADRS score in either the MDDart+ $(\mathrm{r}=0.002, \mathrm{p}=0.988)$ or the MDDart$(\mathrm{r}=-0.254, \mathrm{p}=0.361)$ groups.

Contrast D: MDDart- versus HCart-. Within the predefined ROI no areas were identified where the MDDart- group showed greater $\mathrm{rCBF}$ than the HCart- group. The MDDart- group did however show reduced $\mathrm{rCBF}$ in the left insula compared with the HCart- group (table 4).

Whole Brain Analysis. Contrast A: MDDart+ versus MDDart-. Regions in which MDDart+ patients showed increased $\mathrm{rCBF}$ compared with MDDart- participants included (table 5 and fig. 2A): the supragenual and pregenual ACC, right entorhinal cortex, temporopolar cortex bilaterally, rostral temporal sulcal cortex (junction of superior and middle temporal gyri) bilaterally, ventromedial PFC, left ventrolateral PFC, left lateral orbitofrontal PFC, postcentral gyri and adjacent inferior parietal cortex bilaterally, and precuneus. 
Table 3 | Region-of-interest analysis showing increased $\mathrm{rCBF}$ in the MDD sample versus the $\mathrm{HC}$ sample in the high versus low stress condition (contrast $\mathrm{C})^{a}$

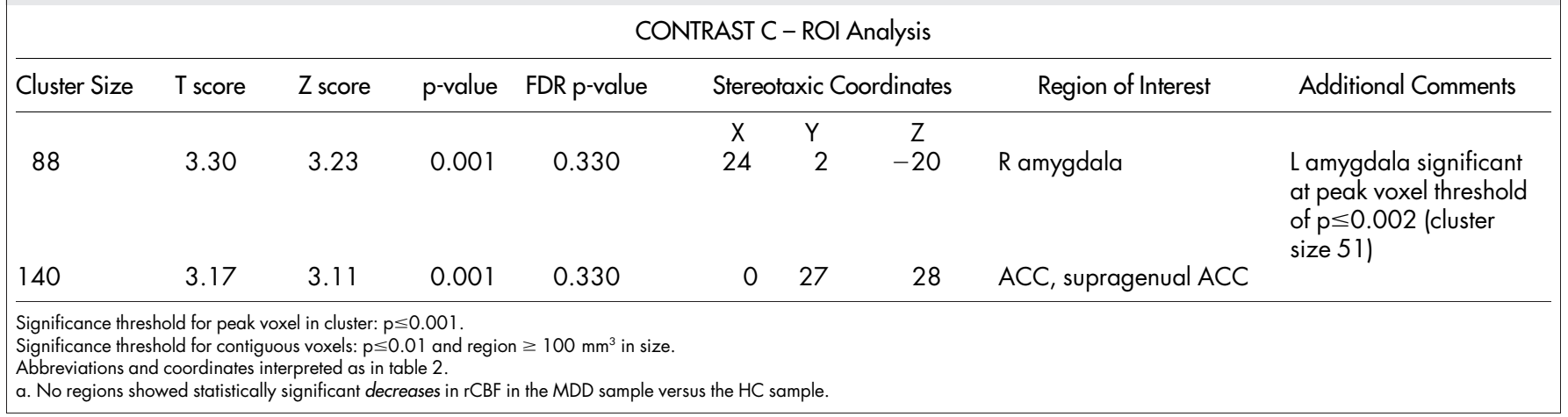

MDD art + patients showed reduced $\mathrm{rCBF}$ compared with the MDD art- patients in the following regions (table 5 and fig. $2 \mathrm{~B}$ ): right anterior insula, left insula, and left frontal operculum.

Contrast B: HCart+ versus HCart-. Relative to the HCart- group the $\mathrm{HCart}+$ group showed higher $\mathrm{rCBF}$ in the right premotor cortex and lower $\mathrm{rCBF}$ in the left parahippocampal gyrus (table 6).

Contrast $C=A-B$. The MDD patients showed a significant increase in $\mathrm{rCBF}$ compared with $\mathrm{HC}$ subjects in response to arterial cannulation in the following regions (table 7, fig. 2C): the right postcentral gyrus, right amygdala, and left temporopolar cortex.

No regions of the brain showed a decrease in $\mathrm{rCBF}$ in MDD patients compared with $\mathrm{HC}$ subjects in response to the arterial line stressor.

In post hoc assessments there was no significant correlation between the normalized activity at the peak voxel in the left temporopolar cortex and the MADRS scores in either the MDDart+ $(\mathrm{r}=0.108, \mathrm{p}=0.508)$ or the MDDart- $(\mathrm{r}=-0.084, \mathrm{p}=0.766)$ groups. In addition, there was no significant correlation between the normalized activity at the peak voxel in the right post-central gyrus and the MADRS scores in either the MDDart $+(\mathrm{r}=0.154, \mathrm{p}=0.344)$ or the MDDart- $(r=-0.208, p=0.457)$ groups. The corresponding relationship at the peak voxel in the right amygdala was not tested because of its proximity to the peak coordinate in the right amygdala in the ROI analysis (see below).

Contrast D: MDDart-versus HCart-. The MDDart- group showed a significant increase in $\mathrm{rCBF}$ compared with HCart- subjects in the right posterior hippocampus (table 8).

No regions of the brain showed a significant decrease in $\mathrm{rCBF}$ in MDDart- patients compared with HCart- subjects.

\section{Discussion}

The main focus of this study was to determine if there is a pattern of $\mathrm{rCBF}$ that distinguishes MDD patients from healthy individuals when they are subjected to an invasive stressor. In general, depressed subjects showed neurophysiological responses to arterial cannulation stress that were exaggerated relative to those of healthy controls in limbic/paralimbic regions of the anterior cingulate cortex, amygdalae and temporopolar cortex. Our most salient results were as follows:

(1) In the supragenual, pregenual ACC, and the ventromedial prefrontal cortex, rCBF increased in MDD patients in the arterial cannulation versus the control condition (contrast A: table 2, fig. $1 \mathrm{~A}$; table 4 , fig. $2 \mathrm{~A}$ ), while the corresponding contrast in healthy controls (contrast B) revealed no significant difference in these areas. These regions form part of a medial prefrontal or "visceromotor" network that plays major roles in modulating the visceral (autonomic, endocrine) responses and processing associated with stress and emotion ${ }^{20}$. Additionally, after controlling for differences in $\mathrm{rCBF}$ in healthy subjects across high and low stress conditions, a more circumscribed region of the ACC showed greater $\mathrm{rCBF}$ in MDD patients compared with $\mathrm{HC}$ subjects (contrast C: table 3, fig. 1C). We have labeled this region as the "supragenual ACC" to signify that it is immediately superior to the genu of the corpus callosum but a variety of different terms - ACC, rostral ACC, anterior midcingulate cortex, perigenual ACC, and pregenual ACC- have been used to describe this region in the literature. The supragenual/pregenual ACC has been hypothesized to be the human homologue of the rat prelimbic cortex which exerts a predominantly inhibitory effect on HPA function via its connections with the bed nucleus of the stria terminalis and the paraventricular nucleus of the hypothalamus ${ }^{19}$, and is highly sensitive to psychological ${ }^{21}$ and physiological stress ${ }^{22}$. In humans, this region is also activated by noxious stimuli, particularly visceral as opposed to cutaneous stimuli, as well as psychological stressors, particularly those associated with the emotion of fear ${ }^{23}$. Critchley et $\mathrm{al}^{24}$ showed that neurophysiological activity in the supragenual and pregenual ACC

Table $4 \mid$ Region-of- interest analysis for contrast $\mathrm{D}$ showing increased $\mathrm{rCBF}$ in the MDD sample versus the $\mathrm{HC}$ sample in the low stress condition (i.e. neither group underwent arterial cannulation) ${ }^{a}$

$$
\text { CONTRAST D - ROI Analysis }
$$

\begin{tabular}{|c|c|c|c|c|c|c|c|c|}
\hline Cluster Size & T score & Z score & $\mathrm{p}$-value & FDR $p$-value & & c Coord & & Region of Interest \\
\hline
\end{tabular}


Table 5 | Results of the whole brain analysis for contrast A showing regions of increased (top panel) and decreased (bottom panel) rCBF in MDDart+ subjects versus MDDart- subjects

CONTRAST A - Whole Brain Analysis

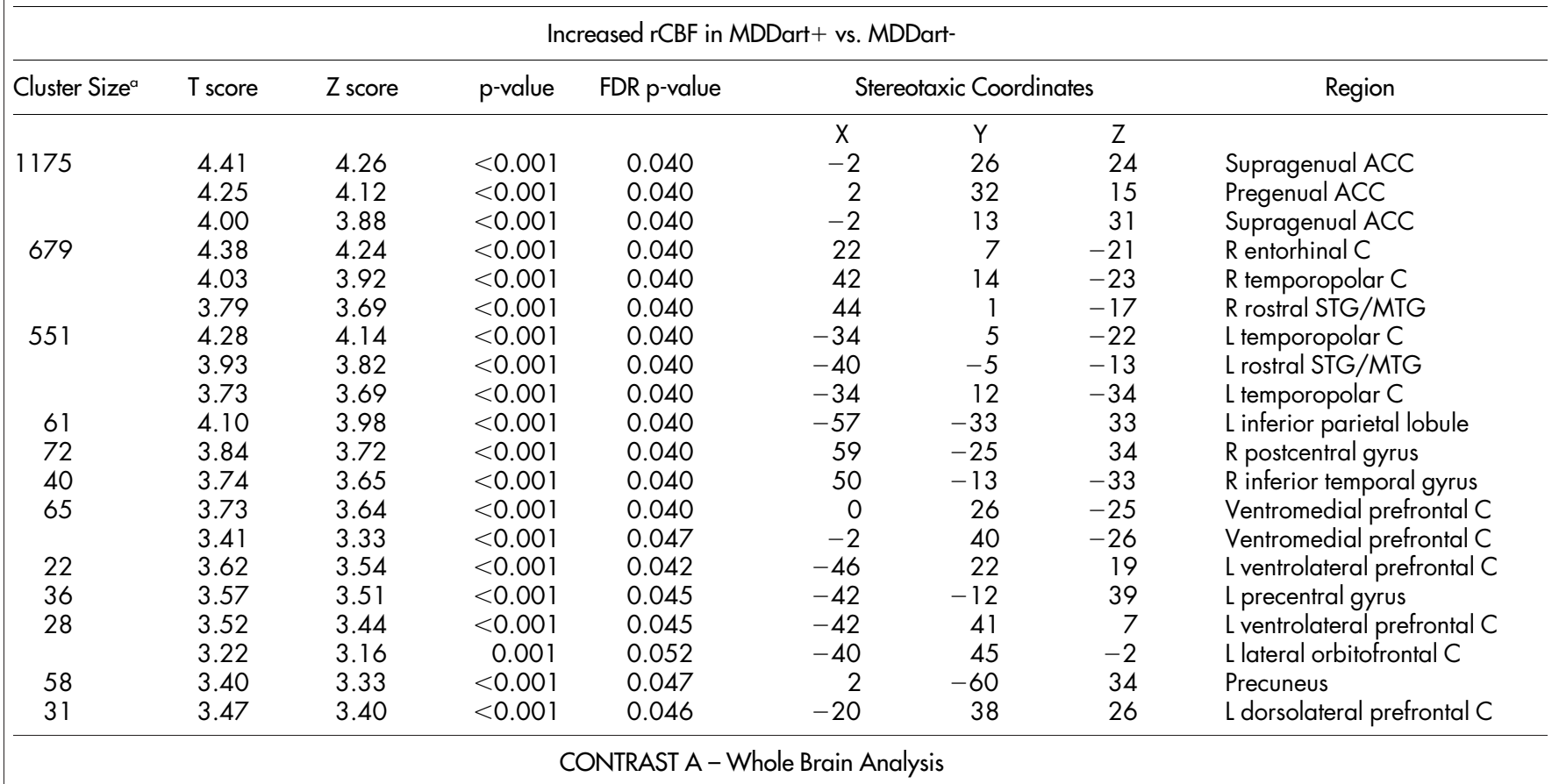

Decreased rCBF in MDDart+ vs. MDDart-

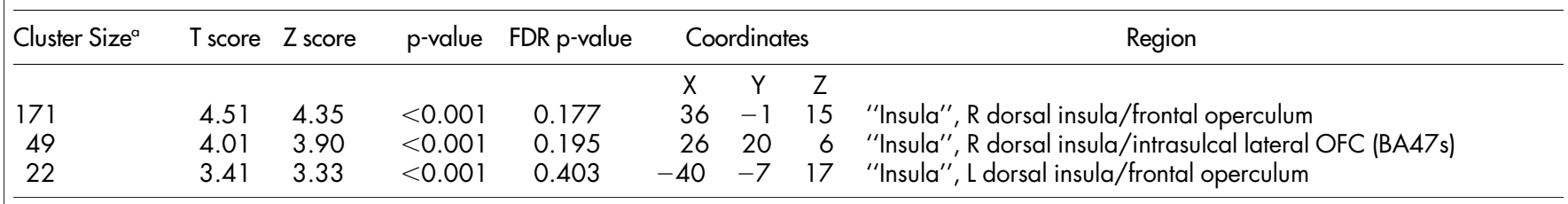

a. Note that the difference in cluster sizes shown here vis a vis those in table 2 reflects the constraint of the anatomical extent of the cluster by the ROI boundaries. Only the local maxima with the three highest voxel t-values within a given cluster are listed here, so these loci should be considered additive to those listed in Tables 2 and 3 in the manuscript.

Significance threshold for peak voxel in cluster: $\mathrm{p} \leq 0.001$, and cluster size of contiguous voxels for which $\mathrm{p} \leq 0.001$ corresponding to $>100 \mathrm{~mm}^{3}$.

Coordinates are interpreted as in table 2.

Abbreviations: ACC - anterior cingulate cortex; C - cortex; STG/MTG - cortex along the superior temporal sulcus at the junction of superior temporal gyrus and middle temporal gyrus; PFC - prefrontal cortex.

correlated with heart rate variability across a variety of mildly stressful cognitive-behavioral tasks. The supragenual ACC is activated by pictures of spiders in phobic individuals ${ }^{25}$, selfadministered but not externally-administered noxious stimulation $^{26}$, the experience of vicarious pain ${ }^{27}$, painful emotions such as social exclusion ${ }^{28}$, and placebo analgesia ${ }^{29}$, suggesting that it is involved in the cognitive and emotional modulation of threatening bodily stimuli. Consistent with this hypothesis, emotions such as anxiety and sadness intensify the negative hedonic quality of experimentally-induced pain, a phenomenon that is correlated with hemodynamic activity of the supragenual $\mathrm{ACC}^{30}$. Further, approximately $75 \%$ of severely ill MDD patients treated with stereotactic lesions of the supragenual ACC region (dorsal anterior cingulotomy) obtain some benefit from the procedure ${ }^{31}$.

There are data to suggest that the stress-associated increase in supragenual and pregenual activity may be related to HPA axis function. Hubbard et al. ${ }^{32}$ recently demonstrated that anxious patients with irritable bowel syndrome (IBS) show a strong positive coupling between BOLD response in the supragenual ACC and the amygdala during expectation of pain. Notably, administration of a CRF antagonist eliminated this positive coupling possibly by normalizing negative feedback by the amygdala on the pregenual $\mathrm{ACC}^{32}$.
(2) Bilateral increases in rCBF of the amygdala were observed in the MDDart+ group compared with the MDDart- group (but not in the HCart+ versus the HCart- groups) in the ROI analysis (contrast $\mathrm{A}$ : table 2, fig. $1 \mathrm{~A}$ ). In contrast $\mathrm{C}$, increased rCBF was observed in the right amygdala in the MDDart+ group compared with the MDDart- group, relative to the HCart + group compared with the HCart- group. An increase in CBF in the left amygdala in the MDDart+ group compared with the MDDart- group relative to the corresponding difference in healthy controls also was observed at a peak voxel threshold of $\mathrm{p}<0.005$ (contrast C: table 3, fig. 1C). Further, an increase in CBF of the right amygdala in the MDDart+ versus MDDart- group relative to controls was observed in the whole brain analysis with a trend towards significance for the left amygdala (contrast C: table 4, fig. 2C). On average, MDDart+ patients who had higher MADRS scores showed significantly greater activity at the peak voxel in the right amygdala derived from contrasts A and C, than MDDart+ patients with lower MADRS scores. Similarly, there was a trend towards a significant positive correlation between activity at the peak voxel in the left amygdala and MADRS scores in the MDDart+ group (fig. 3). The whole brain analysis additionally showed that $\mathrm{rCBF}$ was higher in MDDart+ patients versus MDDart- patients (but not in 


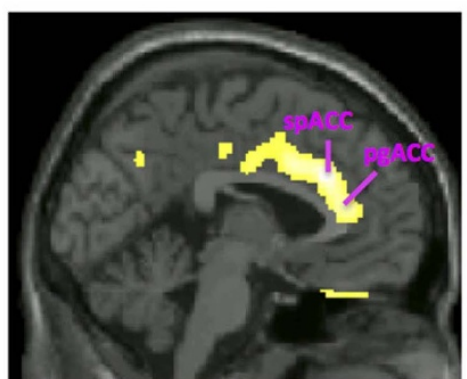

P $x=-2$

A

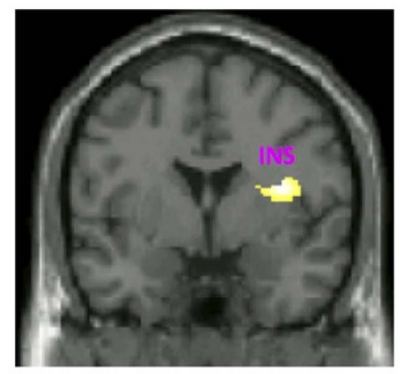

$y=-1$

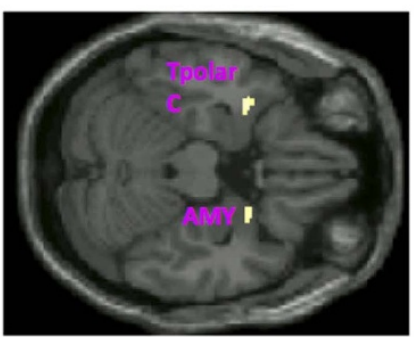

$z=-22$

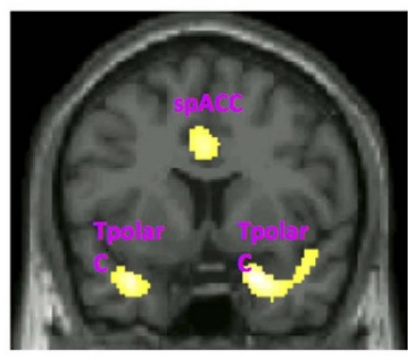

L $y=7$

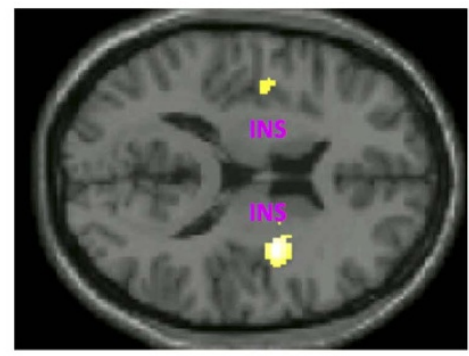

$z=15$

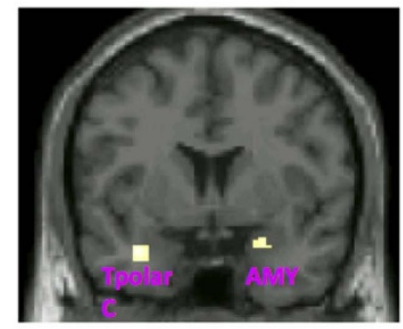

$y=3$

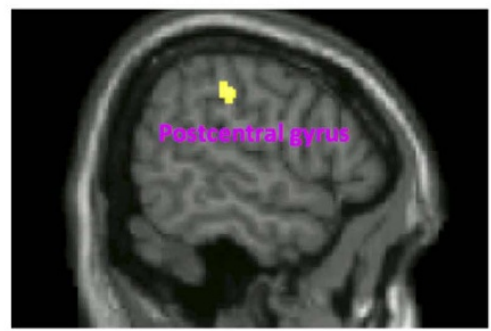

A

$x=59$
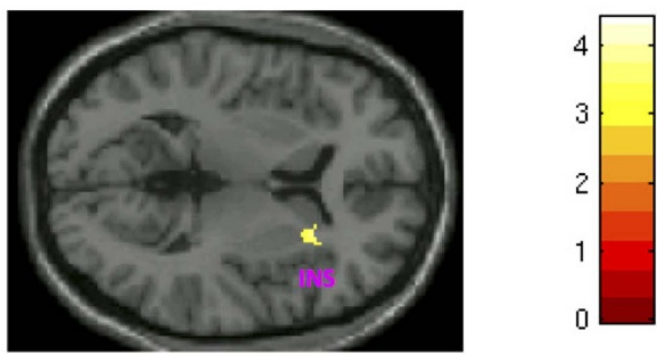

$z=6$
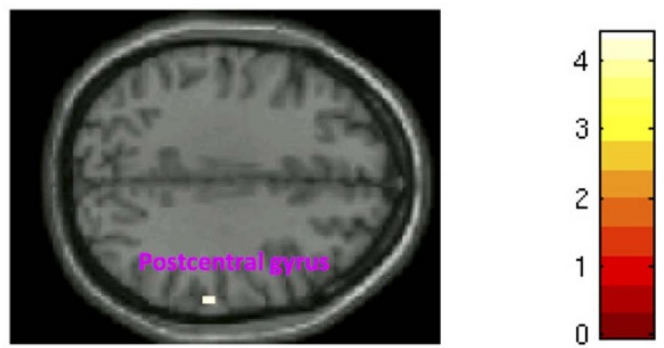

$z=34$

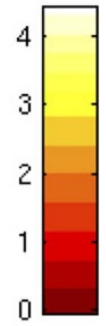

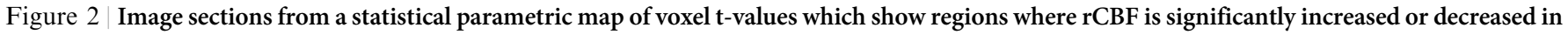

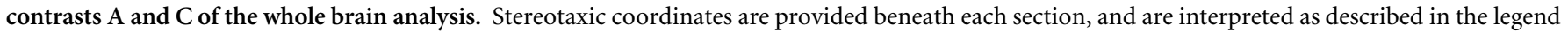
for figure 1. Abbreviations: $\mathrm{A}=$ anterior to anterior commissure, $\mathrm{P}=$ posterior to anterior commissure, $\mathrm{L}=$ left hemisphere, $\mathrm{R}=$ right hemisphere,

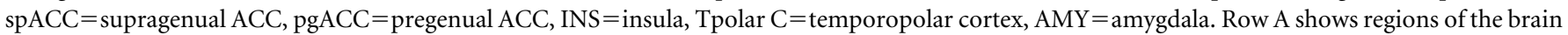

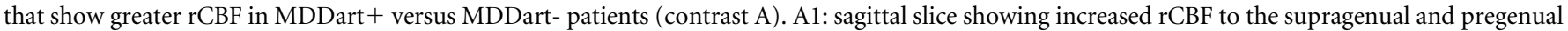

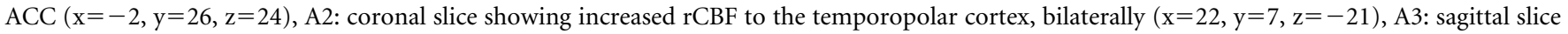

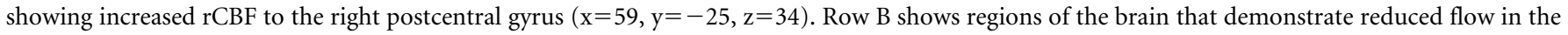
MDDart + group relative to the MDDart- group (contrast A). B1: coronal image showing decreased rCBF to the right dorsal anterior insula/frontal

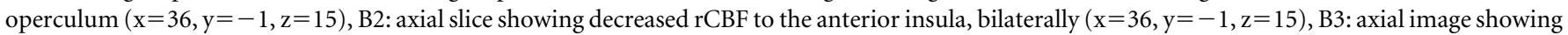
decreased rCBF to the right anterior insula (located dorsal and rostral to the cluster of voxels activated in B2 in the vicinity of the intrasulcal BA47s

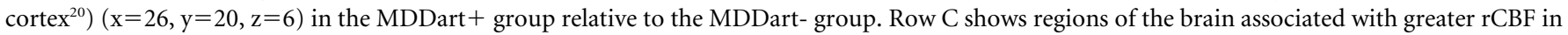

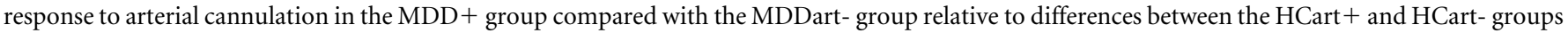
(contrast C). C1: axial slice showing increased rCBF to the left temporopolar cortex and right amygdala (see figure 1 legend and below for amygdala

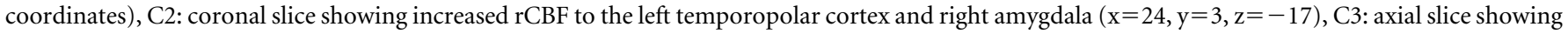

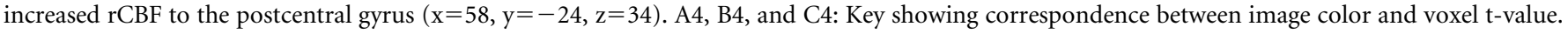

HCart+ versus HCart- subjects) in mesial and rostral temporal cortex, areas that share extensive anatomical connections with the amygdala and the medial prefrontal cortex, namely the right entorhinal cortex, the temporopolar cortex bilaterally, and the cortex along the rostral superior temporal sulcus bilaterally ${ }^{33}$ (contrast $\mathrm{A}$ : table 4 , fig. $2 \mathrm{~A}$ and contrast C: table 6 and fig. 2C).

Depending on the type of stressor and the specific amygdala nucleus examined, chronic stress causes either dendritic atrophy or dendritic hypertrophy of amygdala neurons in rodents ${ }^{34}$, while in humans, structural MRI is suggestive of decreased amygdala volumes in unmedicated patients with bipolar depression ${ }^{35}$. The functional correlates of this stress may be hyperexcitability of the basolateral amygdala (BLA) and bed nucleus of the stria terminalis (BNST) ${ }^{36}$. While glucocorticoids usually act as a brake on hypothalamic CRF release, high levels of glucocorticoids potentiate the release of $\mathrm{CRF}$ from the $\mathrm{BNST}^{37}$ and activate neurons in the $\mathrm{BLA}^{38}$. This increase in excitability of the BLA has been shown to occur in a timeframe relevant to this study. 
Table 6 | Whole brain analysis for contrast B showing regions where $\mathrm{CCBF}$ differed between $\mathrm{HCart}+$ subjects versus $\mathrm{HCart}$ - subjects

Contrast B - Whole Brain Analysis

Increased rCBF in HCart+ vs. HCart-

\begin{tabular}{|c|c|c|c|c|c|c|c|c|}
\hline Cluster Size & T score & Z score & $\mathrm{p}$-value & FDR p-value & \multicolumn{3}{|c|}{ Stereotaxic Coordinates } & Region \\
\hline 23 & 3.67 & 3.58 & $<0.001$ & 0.812 & $\begin{array}{r}X \\
12\end{array}$ & $\begin{array}{c}Y \\
-16\end{array}$ & $\begin{array}{c}Z \\
63\end{array}$ & R premotor cortex \\
\hline
\end{tabular}

Decreased rCBF in HCart+ vs. HCart-

\begin{tabular}{lcccccccc}
\hline Cluster Size & T score & Z score & p-value & FDR p-value & \multicolumn{2}{c}{ Stereotaxic Coordinates } & Region \\
37 & 3.86 & 3.76 & $<0.001$ & 0.928 & -38 & -41 & -8 & L parahippocampal gyrus
\end{tabular}

Significance threshold, abbreviations, and interpretation of the coordinates are as in table 2.

Duvarci and Pare showed that the principal neurons in the rat BLA increased their intrinsic activity within 1-2 hours of the administration of corticosterone ${ }^{38}$. Given that we have previously shown arterial cannulation to induce cortisol production and given that cortisol increases amygdala excitability and CRF release, it is conceivable that the elevation in blood flow to the amygdala in the cannulated MDD patients but not the HCs, is indicative of an impaired neuroendocrine response to cannulation stress in the patients with MDD, such as an abnormal regulatory (negative feedback) response to cortisol secretion.

Henckens et al..$^{39}$ showed that administration of hydrocortisone to healthy men acutely diminished connectivity of the amygdala to both limbic structures such as the hippocampus and hypothalamus as well as connectivity of the amygdala to cortical structures such as the middle frontal gyri and middle temporal gyri. The authors suggest that this weakening of amygdala connectivity may be an adaptive measure to curtail the neuroendocrine stress response but that continuously elevated levels of circulating cortisol in MDD may result in a pattern of chronic amygdala decoupling ${ }^{39}$. This hypothesis receives support from a study that reported that healthy volunteers showed a peak decrease in amygdala and hippocampal activity 25-30 minutes after intravenous administration of hydrocortisone $e^{40}$. Since $\left[{ }^{15} \mathrm{O}\right]-\mathrm{H}_{2} \mathrm{O}$ PET imaging commenced approximately 30 minutes after arterial cannulation (see below), healthy volunteers, but not depressed subjects, may have been able to curtail their glucocorticoid-driven stress response in the time period between arterial cannulation and imaging. Thus, a disturbance of cortisol regulation may have contributed to the stress-associated increase in $\mathrm{rCBF}$ in the amygdalae of patients with MDD.
Regarding physical stressors, the amygdala shows increased neurophysiological response to pain in both healthy subjects ${ }^{41}$ and patients with $\mathrm{MDD}^{42,43}$. Similarly, decreased sensitivity to pain in PTSD is associated with a reduction in the hemodynamic response of the amygdala ${ }^{44}$. Of additional relevance is a recent study showing that inducing a sad mood in healthy subjects enhances pain sensitivity in response to a noxious stimulus. Greater subjective unpleasantness of the pain was correlated with activity in the amygdala bilaterally ${ }^{45}$. Nonetheless we note that we cannot draw any conclusions about the degree of physical discomfort experienced by the MDD versus the HC groups in this study.

The positive correlation between $\mathrm{rCBF}$ in the right (and to a lesser extent, the left) amygdala is consistent with the finding of Abercrombie et al. who reported that regional cerebral metabolism in the right amygdala of depressed subjects was positively associated with negative affect measured using the Positive and Negative Affect Schedule (PANAS) ${ }^{46}$. Our result is also consistent with our previous finding of a significant correlation between Hamilton Depression Rating scores and rCBF in the left amygdala in patients with $\mathrm{MDD}^{47}$. Our study goes one step further by demonstrating that a physical stressor may induce this effect since the correlation between $\mathrm{rCBF}$ in the amygdala and depression severity was not observed in the MDDart- group.

(3) A bilateral increase in $\mathrm{rCBF}$ was observed in the posterior insula (PI) in MDDart+ patients compared with MDDartpatients (contrast A: table 2, fig. 1A; contrast C: table 3, fig. 1). In contrast, decreased rCBF of the left and right dorsal anterior insula (AI)/ frontal operculum was observed in the MDDart+ versus the MDDart- group (contrast A: table 2, fig. $1 \mathrm{~B}$; table 4 , fig. 2 ).

The insula is functionally and cytoarchitecturally differentiated along rostro-caudal lines ${ }^{48}$. While the granular PI is

\begin{tabular}{|c|c|c|c|c|c|c|c|c|}
\hline & & & COI & RRAST C - Wh & $\operatorname{ain} A n$ & & & \\
\hline & & & & creased $\mathrm{rCBF}$ in & Dvs. $\mathrm{H}$ & & & \\
\hline Cluster Size & T score & Z score & $\mathrm{p}$-value & FDR p-value & & xic Coo & ates & Region \\
\hline 44 & 3.64 & 3.55 & $<0.001$ & 0.697 & -34 & 5 & -22 & L temporopolar cortex \\
\hline 19 & 3.30 & 3.23 & 0.001 & 0.697 & 24 & 3 & -17 & R Amygdala \\
\hline
\end{tabular}

Significance threshold, abbreviations, and interpretation of the coordinates are as in table 2.

a. No region showed statistically significant decreases in rCBF for contrast $C$. 
Table 8 | Whole Brain Analysis showing regions of increased $\mathrm{rCBF}$ in the MDD sample versus the $\mathrm{HC}$ sample in the low stress condition (contrast D) ${ }^{\mathrm{a}}$

CONTRAST D - Whole Brain Analysis

Increased rCBF in MDDart- vs. HCart-

\begin{tabular}{lcccccccc}
\hline Cluster Size & T score & Z score & p-value & FDR p-value & \multicolumn{2}{c}{ Stereotaxic Coordinates } & Region \\
\hline 14 & 3.41 & 3.34 & $<0.001$ & 0.972 & 29 & -32 & 4 & R Posterior Hippocampus
\end{tabular}

Significance threshold, abbreviations, and interpretation of the coordinates are as in table 2 .

a. No regions showed statistically significant decreases in $\mathrm{rCBF}$ for contrast $\mathrm{D}$.

closely linked to the somatosensory cortex and parietal operculum, and provides an interoceptive map of the physiological state of the body, the agranular AI is thought to provide more abstract emotional information that flows from this corporeal representation. Specifically, Craig ${ }^{48}$ postulated that sensory information from the PI is initially re-represented in the ipsilateral AI, but then undergoes a second-order remapping in the right $\mathrm{AI}$, allowing for the subjective emotional experience associated with physiological arousal/stress. That is, the AI appears to play a role in translating interoceptive states into subjective feelings.

Consistent with this hypothesis, the AI is activated not only by aversive physical stressors but also by "noxious" psychological stimuli such as watching a loved one in pain ${ }^{49}$, imagining oneself to be in pain ${ }^{50}$ or believing that one is being exposed to harmful mobile phone radiation ${ }^{51}$. Greater activation of the right $\mathrm{AI}$ is also observed in response to painful stimulation after sad mood induction ${ }^{52}$.

Since all of these studies reporting increased activity in the AI in response to noxious stimuli were conducted on healthy volunteers, it could be argued that the decrease in AI blood flow observed in our MDDart+ sample compared with the MDDart- sample is reflective of an abnormal insular response to physiological stress in MDD. This hypothesis is consistent with the finding of Brody et al..$^{53}$ who reported that MDD patients showed increases in glucose metabolism in the left anterior insula ( $\mathrm{x}$ y $\mathrm{z}$ coordinates: $-46,20,8$ versus a secondary peak in our study at $-40,18,6)$ after treatment with interpersonal psychotherapy. (Nevertheless, it should be noted that these coordinates actually localize to the frontal operculum associated with the inferior frontal gyrus, in the stereotaxic atlases of Mai et al..$^{54}$ and Talairach and Tournoux ${ }^{55}$ - see discussion, below). Similarly, a recent meta-analysis of the MDD literature reports decreased activity of the left AI $(-36,7,4)$ during exposure to negative stimuli ${ }^{56}$. Conceivably, the discrepant findings regarding functional activity of the AI in depressed subjects as opposed to healthy controls also may be related to HPA axis function. Hubbard et al. ${ }^{32}$ found that compared with healthy controls, anxious IBS patients displayed a strong negative correlation between the resting $\mathrm{BOLD}$ response of the $\mathrm{AI}$ and the amygdala during expectation of abdominal pain. However, after administration of a $\mathrm{CRF}$ antagonist, the negative coupling between the AI and the amygdala was attenuated.

In contrast, other studies of depressed patients with $\mathrm{BD}$ have demonstrated increased glucose metabolism of the right $\mathrm{AI}^{57}$ $(34,2,2)$ increased $\mathrm{rCBF}$ in the right $\mathrm{AI}$ after induction of sadness $^{58,59}(38,4,0$ and $44,16,4)$, and a decrease in glucose metabolism of the both the AI and PI after successful treatment with paroxetine $e^{60}(-36,2,0 ; 40,22,-2)$ and fluoxetine $e^{61}$ $(-22,22,6$ and $36,14,8)$. Similarly, MDD patients have been reported to show post-treatment increases in glucose metabolism in the ventral $\mathrm{AI}(30,18,-8$ and $-16,18,-16)$ and the midanterior $\operatorname{AI}(30,-2,8 \text { and }-26,-4,8)^{62}$. Consistent with these data, increased activation of the PI, bilaterally, and the left $\mathrm{AI}(-24,24,6)$ in response to noxious heat stimulation in MDD was reported ${ }^{63}$. Moreover Strigo et al..$^{43}$ reported that during anticipation of painful stimuli relative to non-painful stimuli depressed subjects displayed greater activation than controls in the right AI, although the region implicated actually localized to the inferior frontal gyrus $(44,22,9)$.

While most studies show acutely increased activity of the AI in response to negative stimuli, one possible explanation for the decrease in $\mathrm{rCBF}$ in the $\mathrm{AI}$ in the MDDart + versus the MDDart- group is that the decrease in AI activity is indicative of impaired sensory integration under stress. Strigo et al. reported that compared with healthy controls, unmedicated patients with MDD showed a decreased BOLD response in the vicinity of the right AI located in lateral orbital cortex (BA47l; Ongur et al. $\left.{ }^{20}\right)(37,24,-7)$ in response to cues predicting a shift in the intensity of a stimulus from non-painful warmth to painful heat and vice versa ${ }^{64}$. This cortex forms part of the "orbital" or "sensory" prefrontal network described by Ongur et al..$^{65}$ which plays a major role in sensory integration. Strigo et al. speculated that this deficit prevents the MDD patients from attributing accurate emotional value to physiological safety cues ${ }^{64}$. Interestingly, the AI plays a role in fear extinction. At least 3 studies have reported increased activity in the AI during extinction learning in healthy individuals ${ }^{6,67}$. Gottfried and Dolan reported neural activation of the AI (39, 12,9 and $-33,15,12$ ) during the extinction-learning phase of an olfactory conditioning task ${ }^{66}$, while hemodynamic response of the $\mathrm{AI}(-35,14,3$ and $31,20,5)$ was associated with extinction to conditioned shock responses ${ }^{68}$. In a more recent study, volunteers showed an increased hemodynamic response in the vicinity of the AI, located in the frontal operculum $(-40,20,2$ and $40,20,-2)$ but a decreased hemodynamic response in the amygdala during the extinction phase of a cued fear-conditioning task ${ }^{67}$. Conceivably, the changes in $\mathrm{rCBF}$ in the $\mathrm{AI}$ reported here may be related to the suboptimal extinction of fear responses in patients with mood and anxiety disorders ${ }^{69}$.

In sum, the literature on insula function in depression is confusing perhaps because the insula is a large and heterogeneous brain region with a highly complex pattern of internal and external connections. The studies that have implicated the AI in depression have generally reported increased activity in a more ventral region of the AI than reported here and this may be one reason for the discrepancy of our data with some of these aforementioned reports. The coordinates of our peak voxels (tables 2 and 5), are not centered in a region that is classically thought to be agranular AI. Rather according to the anatomical atlases of Mai et al..$^{54}$ and Talairach and Tournoux ${ }^{55}$, the peak voxels in our study are found in the dorsal insula/frontal operculum and in BA47s (Walker 12o in the monkey $)^{20}$. Our group has recently shown the dorsal 

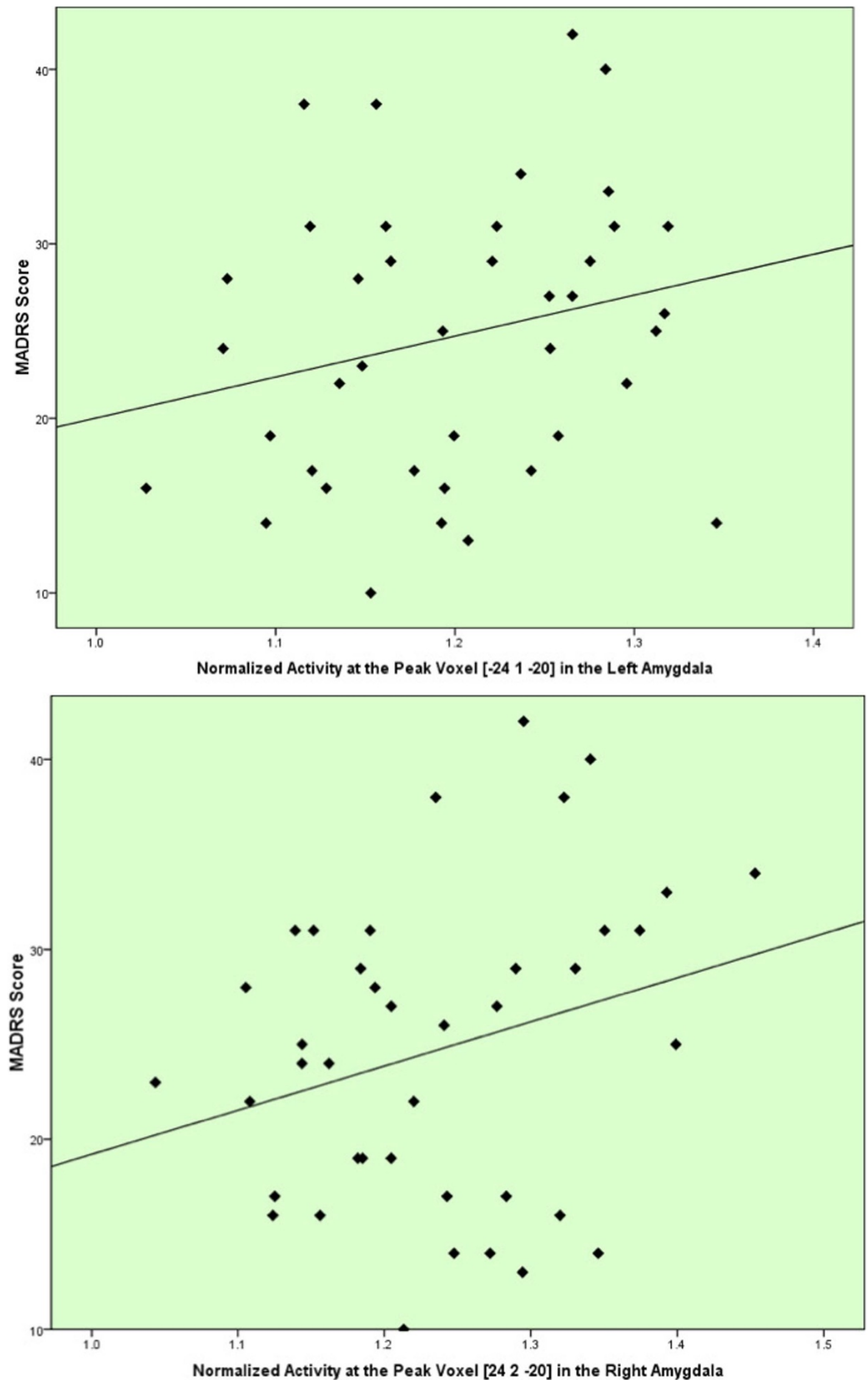

Figure 3 Correlations between the MADRS scores and the normalized activity at the peak voxels in the left amygdala $[x=-24, y=1, z=-20]$ and the right amygdala [24, 2, -20] in the MDDart+ group. The peak voxel for the left amygdala was obtained from the ROI analyses (contrast A, table 2, contrast $\mathrm{C}$, table 3). Note: The normalized activity is unitless because it is a ratio of activity at the peak voxel to mean activity over the whole brain. The solid line represents the line of best fit for the data. 
insula/frontal operculum to be activated specifically in response to interoceptive (as opposed to exteroceptive) stimuli at almost identical stereotaxic coordinates to those reported here $(-37,-3,16$ versus $36,-1,15$ and $37,-3,16$ versus $-40,-7,17)^{70}$. Moreover Avery et al. reported that compared with healthy volunteers, depressed MDD subjects showed a reduction in BOLD activity in response to the eliciting of interoceptive stimuli (stomach, heart, and bladder) that was correlated with depression severity ${ }^{70}$. Clearly, the presence of an arterial cannula is a salient interoceptive stimulus. Conceivably, patients with MDD are impaired at assigning emotional value (including physiological safety cues) ${ }^{64}$ to interoceptive stimuli, thus accounting for the decrease in rCBF in the dorsal AI in the MDDart+ versus the MDDartgroups, but not in the HCart+ versus the HCart- groups. The MDDart+ patients displayed decreased rCBF compared with MDDart- patients in the sgACC (contrast A: table 2, fig. 2A).

The sgACC has been implicated in pain as well as mood disorders $^{71}$. While increased sgACC activity is usually associated with $\mathrm{MDD}^{71}$, increased activity of this region is also associated with pain relief. For example, activation of the sgACC has been reported in conjunction with placebo-induced analgesia ${ }^{72}$, deep brain stimulation-induced relief of phantom limb pain ${ }^{73}$ and habituation to experimentally-induced pain $^{74}$. On the other hand, Lopez-Sola ${ }^{63}$ found that compared with healthy controls, MDD patients failed to deactivate the sgACC and the pregenual ACC during painful stimulation. Conceivably, the cannulation-associated decrease in $\mathrm{rCBF}$ in the sgACC in our sample of individuals with MDD, is reflective of a disturbance in visceromotor network homeostasis which retards extinction of somatic arousal and cannulation-associated stress. This hypothesis is congruent with a recent report that examined the neural correlates of courage as indicated by the ability to overcome fear in people with snake phobia ${ }^{75}$. Allowing a live snake to be brought closer to their heads without succumbing to fear was associated with increased hemodynamic response of the sgACC together with decreased activity of the amygdala. Moreover, the increase in sgACC activity was associated with a decrease in somatic arousal as measured by skin conductance responses.

Increased $\mathrm{rCBF}$ in the right somatosensory cortex and precuneus was observed in the whole brain analysis of the MDD group in the high versus low stress condition (contrast $\mathrm{A}$ : table 4 , fig. $2 \mathrm{~A}$ and contrast C: table 6 , fig. $2 \mathrm{C}$ ).

In the meta-analysis of Apkarian et al. ${ }^{18} 46$ out of 68 studies of healthy subjects showed significant changes in activity of the somatosensory cortex during pain induction. The cluster of increased $\mathrm{rCBF}$ in the right postcentral gyrus is consistent with left-sided arterial cannulation. Somatosensory cortex I (SI) has a somatotopic arrangement and is involved in localization of pain on the body surface. SII, however, contains fewer nociceptive neurons and may play more of a role in spatially directed attention towards the painful stimulus rather than sensorymechanical discrimination of the stimulus ${ }^{76}$. SII may also play a role in the processing of more abstracted pain stimuli. SII is activated by vicarious observation of trauma ${ }^{77}$ and hypnosisinduced pain $^{78}$. In fact, a recent study even reported activation of SI during the processing of pain-related words ${ }^{79}$. Finally, the posterior insula, which also showed increased $\mathrm{rCBF}$ in MDDart+ patients compared with MDDart- patients, contains a major sensory association cortex ${ }^{80}$.

Thus, the increased arterial cannulation-associated $\mathrm{rCBF}$ of the right postcentral gyrus in our MDD group is consistent with 3 non-mutually exclusive possibilities: increased physical sensitivity to the invasive stimulus in MDD, a heightened attentional awareness of the arterial line in our MDD sample compared with the HC sample, and greater physiological stressor-driven emotional processing in MDD. The higher rCBF in the somatosensory cortices in the postcentral gyrus in MDD subjects versus controls under arterial cannulation stress appears particularly noteworthy in light of the "somatic marker hypothesis" of emotion proposed by Damasio and his colleagues. This hypothesis proposes that the visceral or bodily reaction that normally accompanies emotion or unease (the somatic marker) is experienced in a network subserved by both the somatosensory cortices and portions of the ventromedial prefrontal cortex that include the perigenual ACC and medial orbitofrontal cortex ${ }^{81}$. If so, then over-activity of this system in MDD in response to stressors may hypothetically produce the chronic sense of "unease" that is a frequent component of depression.

Similarly, the precuneus has been associated with pain processing in a number of recent imaging studies perhaps because of its role in self-referential processing ${ }^{82}$. The default mode network (DMN) refers to regions of the brain that are thought to mediate self-referential processing, are most active when the brain is in a resting state, and that are largely suspended when the individual is actively engaged in effortful cognitive tasks ${ }^{83}$. DMN regions include the dorsal and ventral mPFC, posterior cingulate/precuneus, parietal cortex, and the superior temporal gyrus (STG) ${ }^{83}$. These regions have been demonstrated to be inappropriately active in patients with MDD, leading Sheline et al. ${ }^{84}$ to hypothesize that patients with MDD have an impaired ability to shift their attention away from the internal milieu to meet external cognitive demands, and others to account for depression-related rumination with this model ${ }^{85}$.

If correct, the DMN model not only explains the salience of negative emotion in MDD but raises the possibility that disproportionate internal bodily surveillance increases the intensity or unpleasantness of somatic signals in MDD. Consistent with this suggestion, chronic pain patients demonstrate abnormally elevated BOLD activity in the DMN when performing a simple visual attention task ${ }^{86}$ and healthy subjects exposed to noxious stimuli show connectivity changes in the posterior cingulate cortex and the precuneus ${ }^{87}$. Thus the increase in $\mathrm{rCBF}$ in the ACC, inferior parietal lobe, precuneus, and STG in the MDDart+ sample compared with the MDDart- sample, but not in the HCart+ sample compared with the HCart- sample, is consistent with the evidence for a proclivity towards higher activity of the DMN in MDD; a predisposition that may be instantiated under conditions of physiological stress.

(6) The MDDart- group showed increased rCBF in the posterior hippocampus compared with the HCart- group. A reduction in hippocampal volume is one of the most widely reported findings in $\mathrm{MDD}^{88-90}$. We have previously suggested that this MDD-associated reduction in hippocampal volume is more pronounced in the posterior hippocampus than the anterior hippocampus. Our group reported a reduction in posterior but not anterior hippocampal volume in unmedicated, remitted patients with MDD compared with healthy controls ${ }^{91}$, as well as a reduction in posterior hippocampal volume in patients with post traumatic stress disorder (PTSD) versus healthy controls ${ }^{92}$. Approximately half of the PTSD group in this study had co-morbid MDD.

The rodent analogue of the human posterior hippocampus is the dorsal hippocampus. Compared with other hippocampal regions, the CA1 neurons in the dorsal hippocampus have been demonstrated to be particularly sensitive to ischemia ${ }^{93}$, possibly because of the dense concentration of NMDA receptors in this region ${ }^{94}$, which may confer vulnerability to glutamate-induced excitotoxicity. To our knowledge this is the first report of elevated $\mathrm{rCBF}$ specifically in the posterior hip- 
pocampus in depressed patients versus healthy controls, and provides support to our previous neuromorphometric findings in depressed populations.

(7) In contradistinction to the widespread differences in $\mathrm{rCBF}$ that were found between the MDDart+ and MDDart- groups in both the ROI and whole brain analyses (tables 2 and 5), the $\mathrm{HCart}+$ and HCart- groups did not show differences in $\mathrm{rCBF}$ in the ROI analysis, and showed only modest differences in $\mathrm{rCBF}$ in the whole brain analysis (table 6). These data potentially support the conclusion that the functional anatomical responses to physiological stress are exaggerated in individuals with MDD.

There is increasing evidence of an overlap in the neural circuits that underlie physical and social pain/stress ${ }^{95}$. Our results thus raise the possibility that individuals who are neurophysiologically resilient to physical stressors may also be resilient to psychological stressors. Conceivably, future research could be aimed at evaluating the feasibility of using the neurophysiological response to a physical stressor as a marker of vulnerability to mood disorders.

A number of limitations deserve mention. This study was not designed to specifically induce pain in participants. We therefore did not administer psychometric instruments to measure pain after arterial catheterization. Thus, although our MDD patients appeared more neurophysiologically sensitive to the stressor of arterial cannulation than HC subjects, we cannot draw any conclusions about differences in their psychological response to arterial cannulation with respect to the subjective experience of pain or distress. Moreover, the subjective experience of arterial cannulation varies across subjects, such that some individuals report more pain and discomfort than others. Arterial cannulation was performed approximately $30 \mathrm{~min}$ utes prior to the scan. Thus the initial discomfort experienced by subjects may have subsided prior to the commencement of scanning. We note, however, that glucocorticoids exert both rapid non-genomic, and slow genomic effects, both of which persist for a number of hours ${ }^{96}$. Henckens et al. ${ }^{97}$ recently reported that administration of hydrocortisone to healthy individuals 75 minutes prior to fMRI scanning modulated amygdala activity. If the neurophysiological changes associated with arterial cannulation reported herein were at least partly related to glucocorticoid function, then MDD patients with and without glucocorticoid resistance would be expected to differ in their neurophysiological response to cannulation. The study would therefore have been strengthened by the administration of endocrine assays that would have allowed us to differentiate between MDD patients with and without glucocorticoid resistance.

Our study was cross-sectional rather than longitudinal in nature and therefore despite the fact that inclusion and exclusion criteria as well as severity of depression was indistinguishable across cannulation versus non-arterial cannulation studies, it is possible that the art + and art- groups differed on unmeasured clinical or genetic traits that accounted for the results.

The results reported here might not be generalizable to other types of stress. For instance, different results may have been obtained with exposure to transient, superficial pain which is commonly used in most experimental manipulation, is possibly less unpleasant than deeper, visceral pain ${ }^{98}$, and may provoke less of an affective response in PET studies ${ }^{99}$.

Finally, although our sample is very large for a PET imaging study the statistical sensitivity of our results was limited by the relatively small sample sizes of the non-cannulated samples. This reduced our power to detect differences between the participants who underwent arterial cannulation relative to those who did not, and reduced power to detect differential sensitivity to arterial cannulation stress between MDD subjects and healthy controls in contrast C.

In conclusion, we raise the possibility that MDD patients are more sensitive - at least neurophysiologically - to invasive physical stressors than healthy individuals. This difference conceivably may account for the increased incidence of somatic-related complaints in MDD. Perhaps visceromotor regions such as the ACC and insula, which evolved to process somatic pain, have been co-opted to process negative emotions. Thus on the neurobiological level, exposure to emotional pain and independent physical pain, may be akin to a "doubledose" of either emotional or physical pain. Further exploration of response to physiological stressors in MDD may enhance our understanding of the neurobiology of emotion.

\section{Methods}

Participants. The participants were drawn from several different PET neuroreceptor mapping studies, all of which were approved by the NIMH Institutional Review Board. All subjects provided written informed consent to participate. Detailed demographic and clinical data appear in table 1.

Sixty-six individuals with MDD and 79 healthy controls participated in PET studies at the $\mathrm{NIH}$. Blood flow images were acquired using $\left[{ }^{15} \mathrm{O}\right]-\mathrm{H}_{2} \mathrm{O}$ before neuroreceptor imaging studies that employed a range of radioligands, only some of which required an arterial input function for tracer kinetic analysis. Thus $51 \mathrm{MDD}$ patients completed $\left[{ }^{15} \mathrm{O}\right]-\mathrm{H}_{2} \mathrm{O}$ scanning with arterial cannulation (MDD art + ) and $15 \mathrm{MDD}$ patients completed $\left[{ }^{15} \mathrm{O}\right]-\mathrm{H}_{2} \mathrm{O}$ scanning without arterial cannulation (MDD art-). Sixty-two $\mathrm{HC}$ subjects completed $\left[{ }^{15} \mathrm{O}\right]-\mathrm{H}_{2} \mathrm{O}$ scanning with arterial cannulation $\left(\mathrm{HC}\right.$ art + ) and $17 \mathrm{HC}$ subjects completed $\left[{ }^{15} \mathrm{O}\right]-\mathrm{H}_{2} \mathrm{O}$ scanning without arterial cannulation (HC art-).

Participants met DSM-IV criteria for MDD based on the Structured Clinical Interview for DSM-IV ${ }^{100}$ and an unstructured interview with a psychiatrist. The following exclusion criteria applied: left-handedness, history of bipolar disorder, treatment with psychiatric medication within 3 weeks of scanning (6 for fluoxetine), cigarette smoking, significant medical or neurological disorders, past head injury with loss of consciousness, serious risk of suicide, meeting DSM-IV criteria for substance abuse within the previous 6 months or substance dependence within the previous 5 years, general MRI exclusion criteria, electrolyte disturbance, anemia, or positive drug, hepatitis or HIV screen. HC subjects had no lifetime history of a psychiatric disorder, and no first degree relative with a mood or anxiety disorder, as measured by the Family Interview for Genetic Studies (FIGS). There were no differences in inclusion/exclusion criteria for subjects receiving arterial cannulation versus those not receiving arterial cannulation.

Twenty individuals in the MDD art + group were medication naive and the remainder had been unmedicated for an average of $93 \pm 120$ weeks. Ten individuals in the MDD art- group were medication naive and the remaining subjects were unmedicated for an average of $28 \pm 9.0$ weeks. This difference in time spent unmedicated was not statistically significant (table 1).

Eight individuals in the MDD art + group and 2 individuals in the MDD art- group had a remote history of substance abuse (alcohol or cannabis). No individuals had a history of substance dependence. Comorbid disorders present in the MDD art+ group included panic disorder (PD) $(n=5)$, post-traumatic stress disorder (PTSD) $(n=4)$, other anxiety disorders $(n=3)$, and eating disorders $(n=2)$. Comorbid disorders found in the MDD art- group included PD $(n=3)$, PTSD $(n=4)$, other anxiety disorders $(n=2)$, and eating disorders $(n=1)$.

Depression severity was rated using the Montgomery-Asberg Depression Rating Scale (MADRS). Mean MADRS scores of the MDD art+ and MDD art- groups were $25 \pm 8.1$ and $23 \pm 5.4$, respectively.

Positron Emission Tomography. The MDD art+ and HC art+ participants underwent right antecubital venous cannulation and left radial artery cannulation prior to PET imaging. The latter procedure was performed by an anesthesiologist in the post-anesthesia care unit of the NIH Clinical Center approximately 30 minutes prior to commencement of the PET scan. EMLA cream was applied and a local anesthetic was injected into the wrist prior to arterial catheterization. The MDD artand the HC art-subjects also underwent right antecubital venous cannulation 30-60 minutes prior to the start of the PET scan.

Each subject underwent two 40 -second emission scans while resting with eyes closed after bolus IV injection of $10 \mathrm{mCi}$ of $\left[{ }^{15} \mathrm{O}\right]-\mathrm{H}_{2} \mathrm{O}$.

Images were acquired in 3D mode on a GE Advance scanner and reconstructed to a $3 \mathrm{D}$ spatial resolution of $6.5 \mathrm{~mm}$ full-width-at half-maximum. Corrections included measured attenuation. The $\left[{ }^{15} \mathrm{O}\right]-\mathrm{H}_{2} \mathrm{O}$ arterial time activity curve was measured with an automated blood counting system which sampled blood at $3.8 \mathrm{ml} / \mathrm{min}$ during the $\left[{ }^{15} \mathrm{O}\right]-\mathrm{H}_{2} \mathrm{O}$ scans in the cases who had arterial cannulae. So that the image data remained comparable between the subjects with versus without arterial input functions, the images of regional tissue radioactivity concentration, which are proportional to $\mathrm{rCBF}^{9}$, were compared after normalizing the data to exclude nonspecific global effects on tissue $\left[{ }^{15} \mathrm{O}\right]-\mathrm{H}_{2} \mathrm{O}$ uptake. 
Regions of Interest. We expected to observe MDD-associated changes in $\mathrm{CCBF}$ in the high-stress condition in the amygdala, ACC and insula. These regions were identified using the Wake Forest University PickAtlas. The ROI were used to constrain the voxel-wise analysis using the Small Volume Correction option within SPM5

Statistical Analysis. Analysis was carried out using SPM5. The two $\left[{ }^{15} \mathrm{O}\right]-\mathrm{H}_{2} \mathrm{O}$ scans were averaged (in order to improve signal-to-noise ratio) and coregistered to a whole brain MR image acquired using an MP-RAGE sequence $(\mathrm{TE}=4.94 \mathrm{msec}$; $\mathrm{TR}=11.6 \mathrm{msec}$, prep time $=725 \mathrm{msec}$; delay time $=1400 \mathrm{msec}$; voxel size $=0.85 \times 0.85 \times 1.2 \mathrm{~mm}$ ). After coregistration, PET images were spatially normalized to the standard T1 template and smoothed using an $8 \mathrm{~mm}$ Gaussian kernel.

Analysis was performed using a general linear model: a $2 \times 2$ ANOVA with diagnosis (MDD versus $\mathrm{HC}$ ) and arterial line (yes versus no - that is, high versus low stress condition) as main factors, and age as a covariate. Results were normalized by global activity using the SPM5 default grand-mean scaling value of 50 .

In order to measure if arterial cannulation differentially affected the rCBF of MDD and $\mathrm{HC}$ subjects, we subtracted the effects of arterial cannulation in the HC group (HCart+ - HCart-) from the effects of arterial cannulation in the MDD group (MDDart+ - MDDart-). In mathematical terms: [(MDDart+ - MDDart-) (HCart +- HCart-) ]. We have labeled these contrasts as $\mathrm{A}-\mathrm{B}=\mathrm{C}$. In addition, we contrasted the MDDart- vs. the HCart- group in order to evaluate group differences in $\mathrm{rCBF}$ that were specifically related to diagnosis (contrast $\mathrm{D}$ ).

For the ROI analyses the coordinates for peak voxel t-values exceeding a threshold of $\mathrm{p}<0.001$ were reported if they were located within a cluster of contiguous voxels for which $\mathrm{p} \leq 0.01$ that was at least $100 \mathrm{~mm}^{3}$ in size ( 13 voxels). To reduce Type II error whole brain analyses were performed post hoc to locate differences in CBF located outside the regions of primary interest. For the whole brain analysis, the coordinates for peak voxel t-values exceeding $\mathrm{p}<0.001$ were reported if they were located within a cluster of contiguous voxels for which $\mathrm{p} \leq 0.001$ that was at least $100 \mathrm{~mm}^{3}$ in size.

In order to test whether the severity of depressive symptoms affected rCBF in MDD patients, we correlated the activity at the peak voxel of each cluster reaching statistical significance in contrast C (interaction) with the MADRS score for that individual. Specifically, the ROI analysis yielded two significant clusters with peak voxels in the right amygdala $[24,2,-20]$ and supragenual ACC $[0,27,28]$. Three clusters in the right postcentral gyrus $[59,-25,34]$, left temporopolar cortex $[-34,5,-22]$ and right amygdala $[24,3,-17]$ reached statistical significance in contrast $C$ in the whole brain analysis. However, the activity at the voxel at coordinate $[24,3,-17]$ in the right amygdala was not evaluated for correlation with the MADRS scores because of its close proximity to the peak voxel coordinate in the ROI analysis [24, 2, -24], which would have rendered the analysis redundant. We previously reported an association between glucose metabolism in the left amygdala and depression severity ${ }^{47}$, and therefore we also conducted a correlation analysis with the peak voxel the left amygdala that reached statistical significance in contrast $\mathrm{A}[-24,1,-20]$. Because of the $a$ priori evidence for a positive association between amygdala activity and severity of depression, we conducted the correlation analyses involving the left and right amygdala with a one-tailed Pearson's correlation coefficient test. All other correlations were conducted using a two-tailed Pearson's test.

The distribution of gender across the 4 subject groups was measured using the chisquared test (two-tailed, $\mathrm{p}<0.05$ ). An ANOVA was used to test for differences in age across the 4 groups (two-tailed, $\mathrm{p}<0.05$ ). Independent sample t-tests (two-tailed $\mathrm{p}<0.05$ ) were used to compare the MDD art + and MDD art- groups on the following variables: number of weeks medication free, age at illness-onset, duration of illness, and MADRS, scores.

1. Liu, R. T. \& Alloy, L. B. Stress generation in depression: A systematic review of the empirical literature and recommendations for future study. Clin Psychol Rev 30, 582-593, doi:10.1016/j.cpr.2010.04.010 (2010).

2. Burke, H. M., Davis, M. C., Otte, C. \& Mohr, D. C. Depression and cortisol responses to psychological stress: a meta-analysis. Psychoneuroendocrinology 30, 846-856, doi:10.1016/j.psyneuen.2005.02.010 (2005).

3. Nugent, A. C., Bain, E. E., Thayer, J. F., Sollers, J. J., 3rd \& Drevets, W. C. Heart rate variability during motor and cognitive tasks in females with major depressive disorder. Psychiatry research 191, 1-8, doi:10.1016/j.pscychresns.2010.08.013 (2011).

4. Drevets, W. C. Neuroimaging abnormalities in the amygdala in mood disorders. Ann N Y Acad Sci 985, 420-444 (2003).

5. Savitz, J. \& Drevets, W. C. Bipolar and major depressive disorder: neuroimaging the developmental-degenerative divide. Neurosci Biobehav Rev 33, 699-771, doi:S0149-7634(09)00006-2 [pii] 10.1016/j.neubiorev.2009.01.004 (2009).

6. Robson, A. J., See, M. S. \& Ellis, H. Applied anatomy of the superficial branch of the radial nerve. Clin Anat 21, 38-45 (2008).

7. Parker, L. et al. Dissociation of adrenal androgen and cortisol levels in acute stress. Horm Metab Res 17, 209-212 (1985).

8. Drevets WC, P. J., Bardgett, M. E., Reich, T., Todd, R. \& Raichle, M. E. Glucose metabolism in the amygdala in depression: relationship to diagnostic subtype and stressed plasma cortisol levels. Pharmacol Biochem Behav 71, 431-447 (2002).

9. Herscovitch, P. in Positron Emission Tomography: Basic Science and Clinical Practice. (eds P. E. Valk, D. L. Bailey, D. W. Townsend \& M. N. Maisey) 283-308 (Springer, 2003)
10. Shulman, R. G., Rothman, D. L., Behar, K. L. \& Hyder, F. Energetic basis of brain activity: implications for neuroimaging. Trends Neurosci 27, 489-495 (2004).

11. Gunnar, M. \& Quevedo, K. The neurobiology of stress and development. Annu Rev Psychol 58, 145-173, doi:10.1146/annurev.psych.58.110405.085605 (2007).

12. Drevets, W. C. et al. PET imaging of serotonin 1 A receptor binding in depression. Biol Psychiatry 46, 1375-1387 (1999).

13. Herman, J. P. \& Cullinan, W. E. Neurocircuitry of stress: central control of the hypothalamo-pituitary- adrenocortical axis. Trends Neurosci 20, 78-84. (1997).

14. McGaugh, J. L. \& Roozendaal, B. Role of adrenal stress hormones in forming lasting memories in the brain. Curr Opin Neurobiol 12, 205-210, doi:S0959438802003069 [pii] (2002).

15. de Kloet, E. R., Joels, M. \& Holsboer, F. Stress and the brain: from adaptation to disease. Nat Rev Neurosci 6, 463-475, doi:nrn1683 [pii] 10.1038/nrn1683 (2005).

16. Critchley, H. D., Mathias, C. J. \& Dolan, R. J. Neuroanatomical basis for first- and second-order representations of bodily states. Nat Neurosci 4, 207-212 (2001).

17. Diorio, D., Viau, V. \& Meaney, M. J. The role of the medial prefrontal cortex (cingulate gyrus) in the regulation of hypothalamic-pituitary-adrenal responses to stress. J Neurosci 13, 3839-3847. (1993).

18. Apkarian, A. V., Bushnell, M. C., Treede, R. D. \& Zubieta, J. K. Human brain mechanisms of pain perception and regulation in health and disease. Eur J Pain $\mathbf{9}$, 463-484 (2005)

19. Radley, J. J., Gosselink, K. L. \& Sawchenko, P. E. A discrete GABAergic relay mediates medial prefrontal cortical inhibition of the neuroendocrine stress response. J Neurosci 29, 7330-7340 (2009).

20. Ongur, D., Ferry, A. T. \& Price, J. L. Architectonic subdivision of the human orbital and medial prefrontal cortex. J Comp Neurol 460, 425-449 (2003).

21. Hains, A. B. et al. Inhibition of protein kinase $C$ signaling protects prefrontal cortex dendritic spines and cognition from the effects of chronic stress. Proc Natl Acad Sci U S A 106, 17957-17962 (2009).

22. Wang, Z. et al. Regional brain activation in conscious, nonrestrained rats in response to noxious visceral stimulation. Pain 138, 233-243 (2008).

23. Vogt, B. A. Pain and emotion interactions in subregions of the cingulate gyrus. Nat Rev Neurosci 6, 533-544 (2005).

24. Critchley, H. D. et al. Human cingulate cortex and autonomic control: converging neuroimaging and clinical evidence. Brain 126, 2139-2152 (2003).

25. Goossens, L., Sunaert, S., Peeters, R., Griez, E. J. \& Schruers, K. R. Amygdala hyperfunction in phobic fear normalizes after exposure. Biol Psychiatry 62, 11191125 (2007).

26. Mohr, C., Binkofski, F., Erdmann, C., Buchel, C. \& Helmchen, C. The anterior cingulate cortex contains distinct areas dissociating external from selfadministered painful stimulation: a parametric fMRI study. Pain 114, 347-357 (2005).

27. Zaki, J., Ochsner, K. N., Hanelin, J., Wager, T. D. \& Mackey, S. C. Different circuits for different pain: patterns of functional connectivity reveal distinct networks for processing pain in self and others. Soc Neurosci 2, 276-291 (2007).

28. Krill, A. \& Platek, S. M. In-group and out-group membership mediates anterior cingulate activation to social exclusion. Front Evol Neurosci 1, 1 (2009).

29. Kong, J. et al. Brain activity associated with expectancy-enhanced placebo analgesia as measured by functional magnetic resonance imaging. J Neurosci 26, 381-388 (2006)

30. Ploghaus, A. et al. Exacerbation of pain by anxiety is associated with activity in a hippocampal network. J Neurosci 21, 9896-9903 (2001).

31. Shields, D. C. et al. Prospective assessment of stereotactic ablative surgery for intractable major depression. Biol Psychiatry 64, 449-454, doi:S0006-3223(08) 00431-9 [pii] 10.1016/j.biopsych.2008.04.009 (2008).

32. Hubbard, C. S. et al. Corticotropin-releasing factor receptor 1 antagonist alters regional activation and effective connectivity in an emotional-arousal circuit during expectation of abdominal pain. The Journal of neuroscience : the official journal of the Society for Neuroscience 31, 12491-12500, doi:10.1523/ JNEUROSCI.1860-11.2011 (2011).

33. Price, J. L. \& Drevets, W. C. Neurocircuitry of mood disorders. Neuropsychopharmacology 35, 192-216, doi:npp2009104 [pii] 10.1038/ npp.2009.104 (2010).

34. Vyas, A., Mitra, R., Shankaranarayana Rao, B. S. \& Chattarji, S. Chronic stress induces contrasting patterns of dendritic remodeling in hippocampal and amygdaloid neurons. J Neurosci 22, 6810-6818 (2002).

35. Savitz, J. et al. Amygdala volume in depressed patients with bipolar disorder assessed using high resolution 3T MRI: The impact of medication. Neuroimage 49, 2966-2976 (2010).

36. Shekhar, A., Truitt, W., Rainnie, D. \& Sajdyk, T. Role of stress, corticotrophin releasing factor (CRF) and amygdala plasticity in chronic anxiety. Stress 8, 209-219 (2005).

37. Makino, S., Gold, P. W. \& Schulkin, J. Effects of corticosterone on CRH mRNA and content in the bed nucleus of the stria terminalis; comparison with the effects in the central nucleus of the amygdala and the paraventricular nucleus of the hypothalamus. Brain Res 657, 141-149, doi:0006-8993(94)90961-X [pii] (1994).

38. Duvarci, S. \& Pare, D. Glucocorticoids enhance the excitability of principal basolateral amygdala neurons. The Journal of neuroscience : the official journal of the Society for Neuroscience 27, 4482-4491, doi:10.1523/JNEUROSCI.0680 07.2007 (2007)

39. Henckens, M. J., van Wingen, G. A., Joels, M. \& Fernandez, G. Corticosteroid Induced Decoupling of the Amygdala in Men. Cerebral cortex doi:10.1093/cercor/ bhr313 (2011). 
40. Lovallo, W. R., Robinson, J. L., Glahn, D. C. \& Fox, P. T. Acute effects of hydrocortisone on the human brain: an fMRI study. Psychoneuroendocrinology 35, 15-20, doi:10.1016/j.psyneuen.2009.09.010 (2010).

41. Mobascher, A. et al. Laser-evoked potential P2 single-trial amplitudes covary with the fMRI BOLD response in the medial pain system and interconnected subcortical structures. Neuroimage 45, 917-926 (2009).

42. Graff-Guerrero, A. et al. Cerebral blood flow changes associated with experimental pain stimulation in patients with major depression. J Affect Disord 107, 161-168 (2008).

43. Strigo, I. A., Simmons, A. N., Matthews, S. C., Craig, A. D. \& Paulus, M. P. Association of major depressive disorder with altered functional brain response during anticipation and processing of heat pain. Arch Gen Psychiatry 65, 12751284 (2008).

44. Geuze, E. et al. Altered pain processing in veterans with posttraumatic stress disorder. Arch Gen Psychiatry 64, 76-85 (2007).

45. Berna, C. et al. Induction of depressed mood disrupts emotion regulation neurocircuitry and enhances pain unpleasantness. Biol Psychiatry 67, 1083-1090, doi:S0006-3223(10)00056-9 [pii] 10.1016/j.biopsych.2012.01.014 (2010).

46. Abercrombie, H. C. et al. Metabolic rate in the right amygdala predicts negative affect in depressed patients. Neuroreport 9, 3301-3307 (1998).

47. Drevets, W. C. et al. A functional anatomical study of unipolar depression. J Neurosci 12, 3628-3641. (1992).

48. Craig, A. D. How do you feel--now? The anterior insula and human awareness. Nat Rev Neurosci 10, 59-70 (2009).

49. Singer, T. et al. Empathy for pain involves the affective but not sensory components of pain. Science 303, 1157-1162 (2004).

50. Ogino, Y. et al. Inner experience of pain: imagination of pain while viewing images showing painful events forms subjective pain representation in human brain. Cereb Cortex 17, 1139-1146 (2007).

51. Landgrebe, M. et al. Neuronal correlates of symptom formation in functional somatic syndromes: a fMRI study. Neuroimage 41, 1336-1344 (2008).

52. Coen, S. J. et al. Negative mood affects brain processing of visceral sensation. Gastroenterology 137, 253-261, 261 e251-252 (2009).

53. Brody, A. L. et al. Regional brain metabolic changes in patients with major depression treated with either paroxetine or interpersonal therapy: preliminary findings. Arch Gen Psychiatry 58, 631-640 (2001).

54. Mai, J. K., Assheuer, J. \& Paxinos, G. (Elsevier, 2004).

55. Talairach, J. \& Tournoux, P. Co-Planar Stereotaxic Atlas of the Human Brain (Thieme, 1988).

56. Fitzgerald, P. B., Laird, A. R., Maller, J. \& Daskalakis, Z. J. A meta-analytic study of changes in brain activation in depression. Hum Brain Mapp 29, 683-695 (2008).

57. Mah, L. et al. Regional cerebral glucose metabolic abnormalities in bipolar II depression. Biol Psychiatry 61, 765-775 (2007).

58. Kruger, S., Seminowicz, D., Goldapple, K., Kennedy, S. H. \& Mayberg, H. S. State and trait influences on mood regulation in bipolar disorder: blood flow differences with an acute mood challenge. Biol Psychiatry 54, 1274-1283 (2003).

59. Kruger, S. et al. Risk and resilience markers in bipolar disorder: brain responses to emotional challenge in bipolar patients and their healthy siblings. Am J Psychiatry 163, 257-264 (2006).

60 . Kennedy, S. H. et al. Changes in regional brain glucose metabolism measured with positron emission tomography after paroxetine treatment of major depression. Am J Psychiatry 158, 899-905 (2001).

61. Mayberg, H. S. et al. Regional metabolic effects of fluoxetine in major depression: serial changes and relationship to clinical response. Biol Psychiatry 48, 830-843 (2000).

62. Mayberg, H. S. et al. Reciprocal limbic-cortical function and negative mood: converging PET findings in depression and normal sadness. Am J Psychiatry 156, 675-682. (1999).

63. Lopez-Sola, M. et al. Effects of duloxetine treatment on brain response to painful stimulation in major depressive disorder. Neuropsychopharmacology 35, 23052317, doi:npp2010108 [pii] 10.1038/npp.2010.108 (2010).

64. Strigo, I. A., Matthews, S. C. \& Simmons, A. N. Right anterior insula hypoactivity during anticipation of homeostatic shifts in major depressive disorder. Psychosomatic medicine 72, 316-323, doi:10.1097/PSY.0b013e3181d07873 (2010).

65. Ongur, D. \& Price, J. L. The organization of networks within the orbital and medial prefrontal cortex of rats, monkeys and humans. Cereb Cortex 10, 206-219. (2000).

66. Gottfried, J. A. \& Dolan, R. J. Human orbitofrontal cortex mediates extinction learning while accessing conditioned representations of value. Nature neuroscience 7, 1144-1152, doi:10.1038/nn1314 (2004).

67. Sehlmeyer, C. et al. Neural correlates of trait anxiety in fear extinction. Psychological medicine 41, 789-798, doi:10.1017/S0033291710001248 (2011).

68. Phelps, E. A., Delgado, M. R., Nearing, K. I. \& LeDoux, J. E. Extinction learning in humans: role of the amygdala and vmPFC. Neuron 43, 897-905, doi:10.1016/ j.neuron.2004.08.042 (2004).

69. Graham, B. M. \& Milad, M. R. The Study of Fear Extinction: Implications for Anxiety Disorders. The American journal of psychiatry, doi:10.1176/appi.ajp. 2011.11040557 (2011).

70. Avery, J., Barcalow, J., Bodurka, J., Drevets, W. C. \& Simmons, W. K. in Society for Neuroscience (Washington, DC, 2011).

71. Drevets, W. C., Savitz, J. \& Trimble, M. The subgenual anterior cingulate cortex in mood disorders. CNS Spectr 13, 663-681 (2008).
72. Zubieta, J. K. et al. Placebo effects mediated by endogenous opioid activity on muopioid receptors. J Neurosci 25, 7754-7762 (2005).

73. Kringelbach, M. L. et al. Deep brain stimulation for chronic pain investigated with magnetoencephalography. Neuroreport 18, 223-228 (2007).

74. Bingel, U., Schoell, E., Herken, W., Buchel, C. \& May, A. Habituation to painful stimulation involves the antinociceptive system. Pain 131, 21-30 (2007).

75. Nili, U., Goldberg, H., Weizman, A. \& Dudai, Y. Fear thou not: activity of frontal and temporal circuits in moments of real-life courage. Neuron 66, 949-962, doi:S0896-6273(10)00467-8 [pii] 10.1016/j.neuron.2010.06.009 (2012).

76. Dong, W. K., Chudler, E. H., Sugiyama, K., Roberts, V. J. \& Hayashi, T. Somatosensory, multisensory, and task-related neurons in cortical area $7 \mathrm{~b}(\mathrm{PF})$ of unanesthetized monkeys. J Neurophysiol 72, 542-564 (1994).

77. Benuzzi, F., Lui, F., Duzzi, D., Nichelli, P. F. \& Porro, C. A. Does it look painful or disgusting? Ask your parietal and cingulate cortex. J Neurosci 28, 923-931 (2008).

78. Raij, T. T., Numminen, J., Narvanen, S., Hiltunen, J. \& Hari, R. Strength of prefrontal activation predicts intensity of suggestion-induced pain. Hum Brain Mapp 30, 2890-2897 (2009).

79. Richter, M., Eck, J., Straube, T., Miltner, W. H. \& Weiss, T. Do words hurt? Brain activation during the processing of pain-related words. Pain 148, 198-205, doi:S0304-3959(09)00456-4 [pii] 10.1016/j.pain.2009.08.009 (2010).

80. Fox, P. T., Burton, H. \& Raichle, M. E. Mapping human somatosensory cortex with positron emission tomography. J Neurosurg 67, 34-43, doi:10.3171/ jns.1987.67.1.0034 (1987).

81. Damasio, A. Descarte's Error: Emotion, Reason, and the Human Brain. (Grosset/ Putnam, Picador MacMillan, 1994).

82. Northoff, G. et al. Self-referential processing in our brain--a meta-analysis of imaging studies on the self. Neuroimage 31, 440-457 (2006).

83. Raichle, M. E. et al. A default mode of brain function. Proc Natl Acad Sci U S A 98, 676-682 (2001)

84. Sheline, Y. I. et al. The default mode network and self-referential processes in depression. Proc Natl Acad Sci U S A 106, 1942-1947 (2009).

85. Drevets, W. C., Bogers, W. \& Raichle, M. E. Functional anatomical correlates of antidepressant drug treatment assessed using PET measures of regional glucose metabolism. Eur Neuropsychopharmacol 12, 527-544 (2002).

86. Baliki, M. N., Geha, P. Y., Apkarian, A. V. \& Chialvo, D. R. Beyond feeling: chronic pain hurts the brain, disrupting the default-mode network dynamics. J Neurosci 28, 1398-1403 (2008).

87. Mantini, D., Caulo, M., Ferretti, A., Romani, G. L. \& Tartaro, A. Noxious somatosensory stimulation affects the default mode of brain function: evidence from functional MR imaging. Radiology 253, 797-804, doi:radiol.2533090602 [pii] 10.1148/radiol.2533090602 (2009).

88. Savitz, J. B. \& Drevets, W. C. Imaging phenotypes of major depressive disorder: genetic correlates. Neuroscience 164, 300-330, doi:S0306-4522(09)00579-X [pii

89. Campbell, S., Marriott, M., Nahmias, C. \& MacQueen, G. M. Lower hippocampa volume in patients suffering from depression: a meta-analysis. Am J Psychiatry 161, 598-607 (2004).

90. Koolschijn, P. C., van Haren, N. E., Lensvelt-Mulders, G. J., Hulshoff Pol, H. E. \& Kahn, R. S. Brain volume abnormalities in major depressive disorder: a metaanalysis of magnetic resonance imaging studies. Human Brain Mapping 30, 37193735, doi:10.1002/hbm.20801 (2009).

91. Neumeister, A. et al. Reduced hippocampal volume in unmedicated, remitted patients with major depression versus control subjects. Biol Psychiatry 57, 935937 (2005).

92. Bonne, O. et al. Reduced posterior hippocampal volume in posttraumatic stress disorder. J Clin Psychiatry 69, 1087-1091 (2008).

93. Lipton, P. Ischemic cell death in brain neurons. Physiol Rev 79, 1431-1568 (1999).

94. Bast, T., Zhang, W. N. \& Feldon, J. Dorsal hippocampus and classical fear conditioning to tone and context in rats: effects of local NMDA-receptor blockade and stimulation. Hippocampus 13, 657-675, doi:10.1002/hipo.10115 (2003).

95. Dewall, C. N. et al. Acetaminophen reduces social pain: behavioral and neural evidence. Psychological science 21, 931-937, doi:10.1177/0956797610374741 (2010).

96. Joels, M., Pu, Z., Wiegert, O., Oitzl, M. S. \& Krugers, H. J. Learning under stress: how does it work? Trends Cogn Sci 10, 152-158, doi:S1364-6613(06)00045-3 [pii] 10.1016/j.tics.2006.02.002 (2006).

97. Henckens, M. J., van Wingen, G. A., Joels, M. \& Fernandez, G. Time-dependent effects of corticosteroids on human amygdala processing. J Neurosci 30, 1272512732, doi:30/38/12725 [pii] 10.1523/JNEUROSCI.3112-10.2010 (2010).

98. Dunckley, P. et al. Cortical processing of visceral and somatic stimulation: differentiating pain intensity from unpleasantness. Neuroscience 133, 533-542 (2005).

99. Treede, R. D., Kenshalo, D. R., Gracely, R. H. \& Jones, A. K. The cortical representation of pain. Pain 79, 105-111 (1999).

100. First, M., Spitzer, R., Gibbon, M. \& Williams, J. (Biometrics Research Dept., New York State Psychiatric Institute, 1995).

\section{Acknowledgements}

We would like to thank Jerry Jacobs and staff at the NIH Clinical Center PET Department for their support. We also thank Michele Drevets and Joan Collins, as well as the staff at the post-anesthesia care unit (PACU) for their clinical support and Shilpa Gandhi, Jacqueline Klaver, Gerardo Solorio, Ghedem Solomon, Ruth Tinsley, and Niara Wright for assisting 
with patients and administrative work. Finally, we acknowledge all those individuals who volunteered to take part in our studies.

\section{Financial Disclosure}

Wayne Drevets, M.D. has consulted for Johnson \& Johnson, Pfizer and Eisai. None of the other authors have conflicts of interest to declare.

\section{Author contributions}

JS wrote the paper and conducted the imaging and statistical analyses, ACN assisted with data analysis, DMC scanned subjects, PJC scanned subjects, RD assisted with data analysis, AN scanned subjects, DRS assisted with data acquisition and provided clinical support, SF assisted with data analysis, $\mathrm{PH}$ runs the
PET center and developed the methods for $\left[{ }^{15} \mathrm{O}\right]-\mathrm{H}_{2} \mathrm{O}$ analysis, WCD designed the study and assisted with the writing of the manuscript. All authors reviewed the manuscript.

\section{Additional information}

Competing financial interests: The authors declare no competing financial interests. License: This work is licensed under a Creative Commons

Attribution-NonCommercial-ShareAlike 3.0 Unported License. To view a copy of this license, visit http://creativecommons.org/licenses/by-nc-sa/3.0/

How to cite this article: Savitz, J. et al. Effects of arterial cannulation stress on regional cerebral blood flow in major depressive disorder. Sci. Rep. 2, 308; DOI:10.1038/srep00308 (2012) 